Portland State University

PDXScholar

$5-21-1975$

\title{
The Application and Evaluation of Goal Attainment Scaling to the Janis Drug Treatment Program
}

Steven W. Kilber

Portland State University

Carol E. Swanson

Portland State University

Follow this and additional works at: https://pdxscholar.library.pdx.edu/open_access_etds

Part of the Clinical and Medical Social Work Commons, Social Work Commons, and the Substance Abuse and Addiction Commons

Let us know how access to this document benefits you.

\section{Recommended Citation}

Kilber, Steven W. and Swanson, Carol E., "The Application and Evaluation of Goal Attainment Scaling to the Janis Drug Treatment Program" (1975). Dissertations and Theses. Paper 1818.

https://doi.org/10.15760/etd.1816

This Thesis is brought to you for free and open access. It has been accepted for inclusion in Dissertations and Theses by an authorized administrator of PDXScholar. Please contact us if we can make this document more accessible: pdxscholar@pdx.edu. 
THE ÄPPLICATION AND EVALUATION OF GOAL ATTAINMENT SCALING TO THE JAN IS DRUG TREATMENT PROGRAM

by

STEVEN W. KILBER

and

CAROL E. \$WANSON

A research practicum submitted in partial

fulfillment of the requirements for a degree of

MASTER OF SOOIAL WORK

Portland State University

1975 
TO THE OFFICE OF GRADUATE STUDIES AND RESEARCH:

The practicum advisor approves the research practicum of

Steven W. Kilber and Carol Swanson presented May 21, 1975.

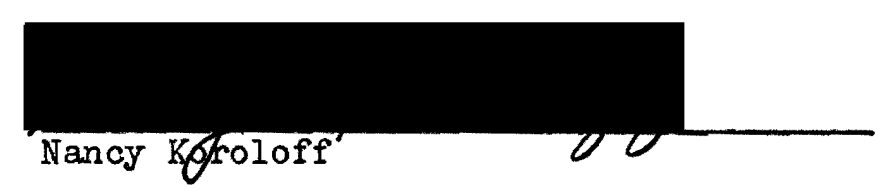


TABLE OF CONTENTS

PAGE

LISTT OF TABLES. • • • • • • • • • • • • • • • • • • • v v

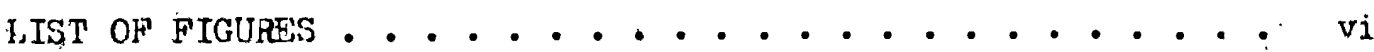

SIFAPTER

I THE IANIS PROGRAM . • . . . . . . . . . . . 1

An Overview. . . . . . . . . . . . . . 1

Janis Gorls and Objectives . . . . . . . 2

The Treatment Program. . . . . . . . . . 2

II THE HAWTHORNE HOUSE PROGRAM . . . . . . . . . . 6

Introduction to Hawthorne House. . . . . . 6

Interest In Goal Attainment Scaling. . . . . 6

Researchers Involvement. . . . . . . . 7

III INTRODUCTION TO GOAL ATTA INMENT SCALING • • • • $\bullet \quad 10$

fockground on Goal Attainment Scaling. . . . 10

Basic Goal Attainment Scaling Procedures • . 11

Goal Attainment Scoring Procedures . . . . 13

Variations of Goal Attainment Scaling. . . . 14

IV APPLICATION OF GOAL ATTA INMENT SCALING TO

HAWTHORNE HOUSE. . . . . . . . . . . . 16

Modification of Goal Attainment Scaling

for the Hawthorne House . . . . . . . 16

The Use of the Individual Plans and

Outcomes System . . . . . . . . . . 19 
$\mathrm{V}$ USE OF SGALE ASSESSMENT TO IMPROVE SCALE QUALITY. • . 30

Background On Goal Attainment Scale

Assessment system .......... 31

The Janis Assessment System. . ... . . . 33

The Use of the IPO Assessment Form . . . . 34

VI EVALUATION OF SCALE ASSESSMENT. . . . . . . . 41

Evaluation of Scale Assessment Data. . . . . 41

Evaluation of the Collation Process. . . . . 47

Summary. . . . . . . . . . 49

VII PROGRAM EVALUATION. . . . . . . . . . . 51

Evaluation of Data on Weekly Attainment

System. . . . . . . . . . 51

Overall Program Evaluation Design. . . . . 59

VIII CONCLUSIONS AND IMPRESSIONS . . . . . . ... 67

Strong Points in the Program ........ 67

Concerns in Using the IPO System . . . . . 67

Summary. . . . . . . . . . . 68

BIBLIOGRAPHY. . . . . . . . . . . . . 70

APPSNDIX A. . . . . . . . . . . . . . . 72

APPENDIX B. . . . . . . . . . . . . . . . 74

APPENDIX C......................... 78 


\section{LIST OF TABLES}

TABLE

PAGE

I Scales Conśtmucted at Hawthorne House -

September 27, 1974 to November 1, 1974. . . . . 9

II Weekly Assessment Soores for Residents . . . . . . 43

III Frequency of Occurrence of Problematic Features. . - 46

IV Scoring Differences Between the Two

Independent Assessors by the Week . . . . . 48 48

V Frequency of Scale Headings Used During the

Eleven Week Period. . . . . . . . . 53

VI Goal Attainment Scores for Residents by

Goal Area............... . . 55

VII Goal Attainment Scores for Residents by

the Week . . . . . . . . . . 58 
1. A Sample Goal Attainment Scale. . . . . . . 12

2 Numerical Values of Outcome Levels. . . . . 13 .

3 Sample IPO Follow-UP Guide. . . . . . . . . 22

4 A Sample: Progress on Completion of Long-Term Goals Form . . . . . . . . . . 23

5 Partial soal Illustrating Use of Subdivision of a Level . . . . . . . . . . 25

6 A Sample; Mutual Planning Form . . . . . . 27

7 A Sample: Weekly IPO Follow-Up Guide . . . . . . 28

8 Goàl Attainment Assessment Scaling. . . . . . 32

9 The Face Section of the IPO Scale Assessment Form. . . . . . . 35

10 The Backside of the IPO Scale Assessment Form. . . . . . . . 36

11 A Sample Problematic IPO Follow-UP Guide. . . . 38

12 Face section of a Sample Follow-Up Guide Scale Assessment Form. . . . . . . 39

13 Baokside of a Sample Follow-Up Guide Scale Assessment Form. . ....... 40

14. Graphic Profile of Assessment Scores. . . . . 45

15. Attainment of Goals of Residents by Goal Area . • 56

16 A Graphic Profile of Attainment Scores For Residents by the Week. ......... 60 
CHAPTER I

THE JANIS PROGRAM

I. AN OVERVIEW

Janis is a residential drug treatment program for drug abusers between the ages of twelve and eighteen designed to rehabilitate the. participants. Five homes, each staffed by two trained residential coordinators and one student accommodate a total of thirty patients at a time. The treatment program consists of daily house meetings led by the residential coordinators, one group therapy session per week led by a psyohiatrio social worker, and individual therapy sessions with a psychiatrist as needed, as well as regular consultation with a psyohologist and psychiatrist. The adolescents enrolled in the program are referred from a variety of agencies, including the Multnomah County Juvenile Court and Home, the Psychiatric Crisis Unit operated by the University of Oregon Health Sciences Center, and other out-patient treatment centers in Portland. Only those adolescents who are motivated to change their behavior are accepted into the Janis program. Janis includes five phases of operation: Referral and Intake Interview, Intensive Residential Therapy, House Residence and Parttime Community Involvement, Out-patient Care, and Follow-up. The patients continue in each phase of the program until the therapist and participant agree that he is prepared to enter the next phase of the program. A social worker designs an educational and vocational program 
for each program participant with that individual. Reality Therapy, Glasser's treatment model, is the basic model for all therapy in the program. 1

\section{JANIS GOALS AND OBJECTIVES}

The overall program goal for Janis is to reduce the level of social dependency and to increase the level of self-sufficiency among tweive to eighteen year-old drug abusers. The target population consists of those living in untenable or marginal living situations who require less than total institutionalization as part of their treatment. Emphasis is on those abusers in the early stages of the criminal justice system.

The treatment objectives toward meeting this goal include:

1. To reduce or alter the patterns of anti-social behavior manifested by Janis participants at time of admission.

2. To improve the educational level and/or vocation related skills of Janis Participants.

3. To obtain and maintain employment for those Janis participants sixteen years and older, not currently engaged in education or trạining program.

4. To maintain Janis residential program graduates in a stable living situation for one year after graduation from the residential program.

\section{THE TREATMENT PROGRAM}

As indicated in Section I, Overview, the treatment program is 
based on William Glasser's "Real ity Therapy." This approach relies on the residents being made responsible for their own treatment, According to Glasser, "The skill of therapy is to put the responsibility upon the patient." Responsibility is defined in two ways. The first way is that the patient must want to change. The second way is that the treatment environment must then demand responsible action from the patient, focusing on here and now behaviors. Glasser says that the proper function of any treatment institution is to provide a warm, disciplined atmosphere in which residents are required to assess their behavior in terms of responsibility. ${ }^{3}$

Glasser goes on to point out the importance of future planning in view of foçusing on the past failures. This leads the patient away from scapegoating the past for his current problems. 4

In the Janis program, this system becomes a four-pronged therapeutic approach. The approach "Emphasizes present behavior problems... behaving in the everyday world is the focus of concern, not psychological mechanisms." 5 The first three prongs are outlined in the original program write-up to include: 1) "Treatment through daily individual sessions with residents focusing on daily issues, mood swings and communication skills;" 2) "Group sessions weekly with a psychiatric social worker dealine with more in-depth issues;" and 3) "Therapeutio community sonsisting of inpatient care directed toward residents taking responsibility for themselves with the help from staff;" 6 4) Family counseling to help the family "change it's method of dealing with the adolescent's behavior."?

The therapeutic community is further defined in the 1974 funding request ${ }^{8}$ to include several elements: 
1. Utilization of daily structure to counteract the previous lack of structure in residents' lives. This includes basic rules; no drugs, no oriminal activities, no interference with basici procedures such as urinalysis, considerate behavior toward others, and completion of therapeutic contract.

2. Development and utilization of peer group identification within the house to help adolescents "to get straight together."

3. Prohibition of use of drug usage while in the program and the monitoring of usage through routine urinalysis.

4. Anti-social acts are confronted immediately with consequences applied for the behaviors.

5. Availability of psychiatric interventions including continuous supervision, use of psychotropic drugs and immediate psychiatric treatment when needed.

6. Utilization of treatment contracts in which "each participant speoifies those areas in which he wants to change and determines just how this will oocur.

Overall then, the Janis Treatment Program may be summarized as a "participatory therapy where the adolescent sets goals and selects services which he believes will help him reach his goals." 9 


\section{REFERENCES - CHAPTER I}

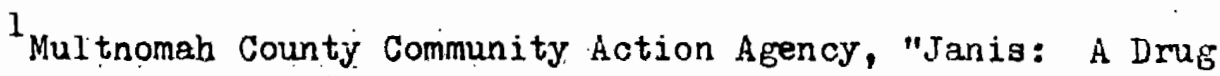
Treatment Proposal," December 1, 1971, p. 22.

William Glasser, Reality Therapy: A New Approach To Psychiatry, (New York: Harper \& Row, 1965), p. 28.

3 Ibid., p. 29.

4 Ibid., p. 37.

5 Janis Project, "Janis: Progress Report," April, 1973, p. 8.

6 Multnomah County Community Action Agency, "Janis: A Drug Treatment Proposal," op.cit., p. 9.

7 Janis Project, "Janis Drug Abuse Services Project," September 1 , 1974, p. 48 .

8 Ibid.; p. $47,48,49$.

9 Janis Project, "Janis: Progress Report," op.cit., p. 10. 


\section{RESEARCHERS INVOLVEMENT}

The researchers entered the program in October, 1974 at the request of the Director of Programs. The purpose was to provide assistance in developing and evaluating the Individual Plans and Oitcomes system in the Hawthorne House. The researchers role was essentially that of evaluation and consultation in program development.

The initial project task included three areas: 1) researching materials and learning about Goal Attainment Scaling model; 2) understanding Janis Program goals and Hawthorne House Program; 3) establishing a working contract between the researchers and the Janis Director of Programs.

The first step, including a review of the literature on Goal Attainment Scaling, was done in October and November. The majority of material reviewed was obtained from the Minneapolis Program Evaluation Project. Also, the application of Goal Attainment Scaling to another setting, Case Management, was examined by the researchers during this time. Case Management Corrections Services had been using Goal Attainment Scaling for one year.

The second step, an understanding of the Janis Program goals and objectives, was imperative in the development of Goal Attainment Scaling in the Hawthorne House Program. A series of meetings and discussions were held.with the Director of Programs and the Hawthorne House staff to gain an understanding of the Janis Program. This understanding was particularly.important because of the uniqueness of each of the Janis treatment houses. Understanding the needs of the staff and of Hawthorne House was essential in providing effective consultation. The researchers 
understood that the primary committment and responsibility to developing and maintaining the program was with the Hawthorne House staff. The relationship between researchers and staff that developed during the meetings allowed the researchers to give input and suggestion to the staff while the primary responsibility for the program remained essentially with the Hawthorne staff.

The Hawthorne House had been using the IPO System for one month prior to the researchers involvement. A review of the scales used during this time gave the researohers some information on how the 'program was being utilized. The number of different scales and the frequency of use between September 27, 1974 to November 1, 1974 is included in Table $I$. Analysis of scale headings indicates the predominate use of the IPO system was for house maintenance issues. Goals in attendance of group therapy, completion of chores, and completion of IPO's themselves, accounting for three of the four most frequently used scales. (See Table I, p. 9).

The third step, developing a written agreement with the Janis Director of Programs, was the outcome of steps one and two. This written agreement is included in Appendix A. Because of the researchers limited time frame, it was particularly important to clarify what the research project goals and limits were. 
SCALES CONSTRUCTED AT HAWTHORNE HOUSE SEPTEMBHR 27, 1974 to NOVEMBER 1, 1974

\begin{tabular}{|c|c|c|c|c|c|c|c|c|c|c|c|c|c|c|c|}
\hline $\begin{array}{l}\text { Scales Presently Used } \\
\text { or Being Used }\end{array}$ & & & & & & & & & & & & & & & Frequency \\
\hline Group. . . . & & - & • & & & & & & & & & & & 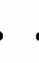 & 22 \\
\hline Chores . . . • & - & - & • & • & & , & & & & 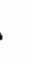 & & , & , & , & 22 \\
\hline Job Interviews . & - & • & & & & & & & & & & & 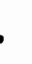 & - & 9 \\
\hline Clinton School Ad. & - & - & • & & 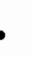 & . & 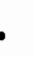 & $\bullet$ & • & • & & • & • & • & 1 \\
\hline IPO. • • • • • • & - & - & & • & • & • & • & 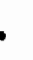 & & 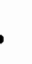 & & • & • & • & 5 \\
\hline GED Test . . . . & 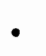 & - & • & & • & • & 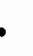 & 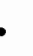 & 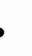 & 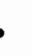 & & 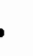 & . & • & 4 \\
\hline College. . . . & • & - & • & & & • & 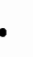 & 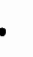 & 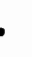 & • & & 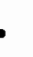 & • & • & 4 \\
\hline College Attendance & - & - & & • & • & • & • & • & 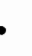 & • & & $\bullet$ & • & $\bullet$ & 1 \\
\hline Personal Meeting . & - & - & • & • & • & • & • & • & 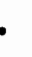 & $\bullet$ & . & • & • & . & 2 \\
\hline College Preparatior & . & • & • & • & • & • & 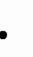 & 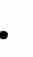 & 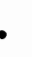 & 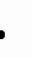 & 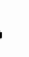 & • & • & • & 2 \\
\hline School . : . . & - & - & • & 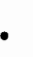 & • & • & 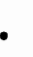 & 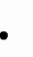 & 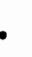 & 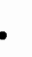 & & 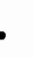 & • & • & 1 \\
\hline School Attendance. & . & - & 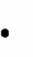 & 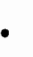 & 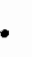 & 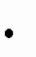 & 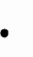 & 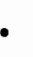 & 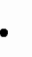 & 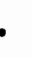 & & 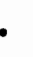 & $\bullet$ & • & 3 \\
\hline Job - attendance . & . & - & & & & 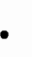 & 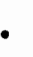 & 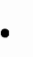 & 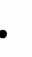 & 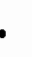 & & 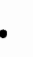 & • & • & 2 \\
\hline GED - studying . . & - & - & & & & & & & • & • & & • & • & • & 1 \\
\hline GED - hours studie & a. & - & & & & & & & & & & • & • & • & 2 \\
\hline Jobs - Places visi & ted & d. & $\bullet$ & & & & & & • & • & & $\bullet$ & • & - & 1 \\
\hline GED - Grammar Test & . & - & & & & & & & & & & 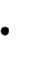 & • & - & 1 \\
\hline Part-time Job. . & . & - & & & & & & & & & & & & 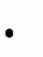 & 2 \\
\hline Parents visits . & . & $\bullet$ & & & & & & & & & & & & • & 1 \\
\hline Work Attendance. . & - & - & & & & & & & & & & & $\bullet$ & . & 1 \\
\hline TOTAL - 20 scales & & & & & & & & & & & & & & & \\
\hline
\end{tabular}




\section{CHAPTER III}

\section{INTRODUCTION TO GOAL ATTA INMENT SCALING}

\section{BACKGROUND ON GOAL ATTA INMENT SCALING}

Goal A ttainment Scaling referred to as GAS, is a system in describing and evaluating problems and objectives. It can be used for either treatment objective-setting or outcome measurement purposes. ${ }^{1}$ GAS, originally developed in a community mental center, has since been adapted to a variety of human services programs.

Goal Attainment Scaling was developed by Drs. Thomas Kiresuk and Robert Sherman of the Hennipin County Mental Health Clinic, luinneapolis, Minnisota. It was developed in the response to a need by mental health professionals for effective evaluation of mental health services. The technique was implemented by the Program Evaluation Project, headed by Dr. Kiresuk and funded through the National Institute of Mental Health. The Program Evaluation Project, PEP, examined the feasibility, reliability and validity of the Goal Attainment Scaling approach. 2

This chapter begins with a discussion of basic Goal Attainment Scaling Procedures. The next part deals with utilizing Goal Attainment Scaling for evaluation purposes. The final section describes the flexibility of Goal Attainment Scaling. 
II. BASIC GOAL ATTA INMENT SCALING PROCEDURE

There are many variations on the exact pattern of Goal Attainment scaling. They all rely on the four basic steps:

Step 1: Collection of information about the person for which goals will be scaled.

Step 2: Specification of the major areas where change would be realistic and helpful.

Step 3: Development of specific, behavioral predictions for a series of outcome levels for each major area.

Step 4: Scoring the outcomes at a later follow-up time.

The first step, collection of information, may come from a variety of sources, such as client statements, reports from spouse, relatives, or other agencies. How the information is gathered depends upon the setting. A common approach for information collection is from client interviews.

The second step involves designation of problem areas for the client. The problem areas are delineated from the information collection in Step $\hbar 1$. Problem areas are defined as undesirable behaviors which could be minimized or favorable behaviors which could be increased.

The process of selecting problem areas may be carried out by the clinician alone, the client alone, the clinician and the client together or another involved party, such as the family. This procedure varies to fit the needs of the agency.

The designated problem areas are then recorded on a Goal Attainment Follow-Up Guide. Each problem area is used to develop a five 
level scale of possible behavioral outcomes. The following figure illústrates one problem area and a developed scale, as how it would appear on a follow-up guide.

\begin{tabular}{|l|l|}
\hline $\begin{array}{l}\text { Levels of predicted } \\
\text { attainment }\end{array}$ & $\begin{array}{l}\text { A. } \\
\text { Scale Heading } \\
\text { (Interest in finding } \\
\text { work) } \\
\text { Employment }\end{array}$ \\
\hline $\begin{array}{l}\text { Most favorable outcome } \\
\text { thought likely }\end{array}$ & $\begin{array}{l}\text { Client employed full } \\
\text { time \& self-supporting }\end{array}$ \\
\hline $\begin{array}{l}\text { More than expected } \\
\text { outcome }\end{array}$ & $\begin{array}{l}\text { Client employed full } \\
\text { time by end of treatment } \\
\text { Heading) }\end{array}$ \\
\hline $\begin{array}{l}\text { Expected level of } \\
\text { outcome }\end{array}$ & $\begin{array}{l}\text { Client employed part time } \\
\text { by end of treatment }\end{array}$ \\
\hline $\begin{array}{l}\text { Less than expected } \\
\text { outcome }\end{array}$ & $\begin{array}{l}\text { client had job but lost } \\
\text { it by end of treatment } \\
\text { Buvels } \\
\text { of } \\
\text { Predic- } \\
\text { tion }\end{array}$ \\
\hline $\begin{array}{l}\text { Most unfavorable } \\
\text { outcome thought likely }\end{array}$ & $\begin{array}{l}\text { client did not obtain job } \\
\text { by end of treatment }\end{array}$ \\
\hline
\end{tabular}

\section{Figure 1. A sample Goal Attainment Scale.}

The problem area to be scaled, is given a title to reflect a general behavioral concerm. The title is entered under the box A. "Scale Heading," of above. The titles inizy be general, conceptual areas that reflect the content of the scale.

The third step in Goal Attainment Scaling procedure is developing five specific predictions of the outcome in each problem area. This is indicated by letter $B$. on the Figure 1 . The prediction includes a time designation at which the follow-up measurement will take place. The five specific predictions make a behavioral continuum of 
possible client outcomes. These five outcomes provide a range from "most favorable outcome thought likely," "more than expected level of outcome," "expected level of outcome," "less than expected outcome," "most unfavorable outcome thought likely." Predictions should be realistic and relevant to the client. These five levels with behavioral predictions assigned to them, compromise a scale. The "expected" level of outcome represents the most realistic prediction of the change in client's behavior during treatment. In developing scales on the follow-up guide the expected level of outcome should be constructed first.

III. GOAL ATTA INMENT SCORING PROCEDURES

Goal Attainment scoring is based on assigning numerical values to the five possible levels of outcome. These numerical values can be used to compute a score reflecting the clients outcome from treatment. The PEP used a numerical value range of -2 to +2 as indicated below.

\begin{tabular}{|l|c|}
\hline $\begin{array}{l}\text { Most favorable } \\
\text { outcome }\end{array}$ & +2 \\
\hline $\begin{array}{l}\text { More than expected } \\
\text { level }\end{array}$ & +1 \\
\hline $\begin{array}{l}\text { Expected level of } \\
\text { outcome }\end{array}$ & 0 \\
\hline $\begin{array}{l}\text { Less than expected } \\
\text { level }\end{array}$ & -1 \\
\hline $\begin{array}{l}\text { Most unfavorable } \\
\text { outcome }\end{array}$ & -2 \\
\hline
\end{tabular}

Figure 2. Numerical values of outcome levels. 
The numerical values can be used to provide two different scoring measures: 1) whether or not the expected level of outcomes were reached; and 2) whether or not change occured. ${ }^{3}$ In measuring client change, the follow-up guide is marked to reflect the level of functioning of the client at the time of intake. The guide is marked again at follow-up time to reflect the clients functioning then. The score is determined by the change between intake and follow-up levels of functioning.

The follow-up interview occurs at a specified time after treatment has started. The procedure for the follow-up interview varys with the agency. The scores can be used for feedback to administrators, clinician's or clients. The scores reflect "whether or not treatment accomplished what it was supposed to accomplish." 4

IV. VARIATIONS OF GOAL ATTA INMENT SCALING

There is a wide range of applications and variations of GAS which can be used to meet the needs of specific agencies. The use of the methodology is expanding as more knowledge is gained around its possible uses. The method is flexible to many different settings. The next chapter will discuss in detail a variation of GAS developed for the Janis Program. 


\section{REFERENCES - CHAPTER III}

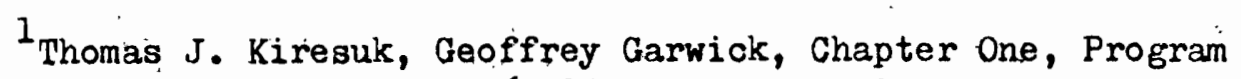
Evaluation Project Report, 1969-1973, Basic Goal Attainment Scaling: Procedures, 1974, p. 3.

$$
\begin{aligned}
& 2 \text { Ibid, p. } 3 . \\
& { }^{3} \text { Ibid, p. } 6 . \\
& { }^{4} \text { Ibid, p. } 7 .
\end{aligned}
$$




\section{APPLICATION OF GOAL ATTAINMENT SCALING \\ TO THE HAWTHORNE HOUSE}

The Janis Individual Plans and Outcomes system, abbriviated to IPO system, is a modification of Goal Attainment scaling. The modifications were designed to meet the requirements of the Janis Program and its target population. The modifications make the IPO system a therapeutic tool in itself as well as providing a measure of treatment success. The following are six specific modifications contained in the Hawthorne IPO system. The features are followed by a step-by-step description on how the system works.

\section{MODIFICATIONS OF GOAL ATTAINMENT SCALING} FOR THE HAWTHORNE HOUSE

\section{Resident Involvement}

The resident is involved in his own goal planning and goal achieving. Wutual planning conferences are held between the resident and staff to plan out goals. The resident commits himself to the goal in a contract format. This is done in a Mutual Planning sheet (Figure 6., page 27). The resident lists his goals and the mutually agreed commitment toward meeting the goal. The commitments are written as specific, measurable behaviors the achievement of which can be measured objectively. The mutual planning fits nicely into the treatment framework. The resident is responsible for the goal selected, 
and held responsible for his action in attaining the goals. The IPO is a reality check for the resident, constantly reminding him of why he is in the program, and providing reality feedback on his behaviors in attempting to reach his goals.

\section{Realistic Achievable Goals}

An important benefit for the resident involvement comes from the experience of setting realistical goals and then achieving the goals. Most of the adolescents referred to the program have long histories of failure. The systematic achieving of goals breaks through much of the failure posture of the residents. The goals used on IPO's are success oriented. In the mutual planning conference the focus of effort is to help the resident set realistic goals.

\section{Standardized Goal Areas}

Related to the first two features is the nature of the goals. The types of goals which the program can help residents meet have been standardized. The goals consist of two types: program goal and personal. growth goals. Program goals are related to specific treatment objectives of the Janis Program. The objectives are discussed in CHAPTER I. The objectives are translated into three goal areas on the IPO: 1) Educational and Vocational Skill Development; 2) Financial Independence, including employment and saving earnings; 3) Post Placement Living, including where the resident plans to go after graduation, plus specific skills needed to make that plan a success. The personal growth goals provide the fourth goal area. These are personal ohange goals selected by the residents. 


\section{Positive Goals}

The fourth unique feature is focusing goals on positive behaviors. Although the residents come to the program because of extensive illegal or anti-social behavior, the goals used to focus treatment avoid these negative behaviors. Coals must be positive and constructive in order to be used on the IPO's. This focuses the resident away from his past problems and his negative self-concept, and toward the issue of "What good things in life do I want? and How do I get them?"

\section{Resident As Source of Information}

The fifth feature is the reliance on the resident as the primary source of information on attainment. Only in special situations has information from other sources been used to determine the attainment level. This is principally for therapeutic reasons to establish trust and to re-emphasize the residonts responsibility for his own progress.

\section{Integrated Lons-Term And Short-Term Goals}

To strengthen and bring immediacy to the IPO program, an integrated system of long-term and short-term IPO's is employed. This feature is essential for adolescents whose focus is relatively short-term, who are inexperienced in goal setting and achieving and who tend to change goals along with moods and clothes. The short-term IPO's are done weekly and they supplement the previously established long-range goals. The weekly IPO contains program goals that are incremental or additive toward the long-range goal. Integrated system teaches the process of breaking a goal down into small achievable steps. 
The weekly IPO provides the bulk of success and goal setting experience for the resident. They provide the most real and relavent feedback on the residence performance. They also provide the repeated message that the resident is responsible for his own actions.

The long-range goals provide the overall purposefulness of residence at Janis. They provide the stability over the day-to-day, week-to-week fluctuations in the residents personality. The long-term IPO's provide the measure of progress in treatment, using a monthly review system and a time table of steps toward the long-term goal. The long-term IPO provides the program evaluation component, the measure of success which is defined as the ability of the program to help the resident.

\section{USE OF THE INDIVIDUAL PLANS AND OUTCOMES SYSTEM}

The basic stmucture of the GAS, and the special Janis features previously discussed, have been combined into the IPO system. The system begins at intake for the resident.

\section{Intake}

Referrals received are screened for appropriateness based on referral information and personal and family interviews. If an adolescent is seen appropriate, one of the five Janis houses is selected for him based on his needs. An intake interview is then held with the child, parents, caseworker, house s.taff and intake worker. The program and expectations of Janis are presented to him including the purpose and purposefulness of the Janis program. He is told of his expectations to work on change, and of the change contract. If 
he is going into the Hawthorne House he is told about the IPO system.

\section{Long-Term Goals}

If he is accepted to Hawthorne, he is given two weeks to work with the house parents to develop the long-term goals. He is required to set at least one goal in each program area. These goals are then transcribed onto a form, Progress on Completion of Long-Term Goals, Figure 4, with the specific steps toward completion laid out by the resident and house parent together.

The resident at this point establishes his own graduation date from the program. The date of termination is one of the most crucial commitments requested of the resident. It provides a sharp awareness of the reality that Janis is only a temporary home, that there is urgency in working on the goals. The definite termination date generally helps the termination be more constructive for the resident. With the establishment of long-term goals, the house parents then scale the goals on the Individual Plans and Outcomes Follow-Up Guide.

The key element is the translation of the residents commitment to the expected level of functioning. This is crucial in making the follow-up guide a statement of the residents commitment. It helps the resident feel relevance in the follow-up guide, and it provides an implicit message that "we expect you to make your commitment." These long-term follow-up guide are marked for level of functioning at Intake, and are filed away until the completion date.

The long-range IPO's can be scored two different ways. They can be scored to provide a measurement of change in the residents during 
treatment, or they can be used to measure the program's effectiveness in helping residents meet their goals. If measurement of change is desired, a scoring system involving marking the follow-up guide for intake level and for follow-up level can be utilized. A score for the change can be obtained by using a procedure such as the Program Evaluation Project. If measurement of attainment of goals is desired, the scoring system described for short-term IPO's discussed in the next section, can be used.

The long-range IPO system is illustrated in the next two pages to clarify the process described. The examples are fictional so as not to divulge confidential information about any of the residents. The "X" on the follow-up guide, Figure 3, indicates baseline level, or level at intake, with the comments section used to clarify the actual behavior at intake time.

The long-term goals can retain some flexibility. The residents progress sheet can be changed to reflect new long-range goals. This is done at the monthly case review process. Changing long-term goals requires carêful consideration before beinğ done. Once a long-term goal is changed it must be rescaled and marked for baseline level of behavior, the level at which the resident is at the time of the change.

\section{Weekly IPO System}

The weekly IPO's constitute the major staff time commitment in this program. The importance they play in the therapy has been discussed. The weekly IPO system begins for the resident as soon as he establishes long-term goals.

The weekly IPO begins in the mutual planning conference on Sunday 


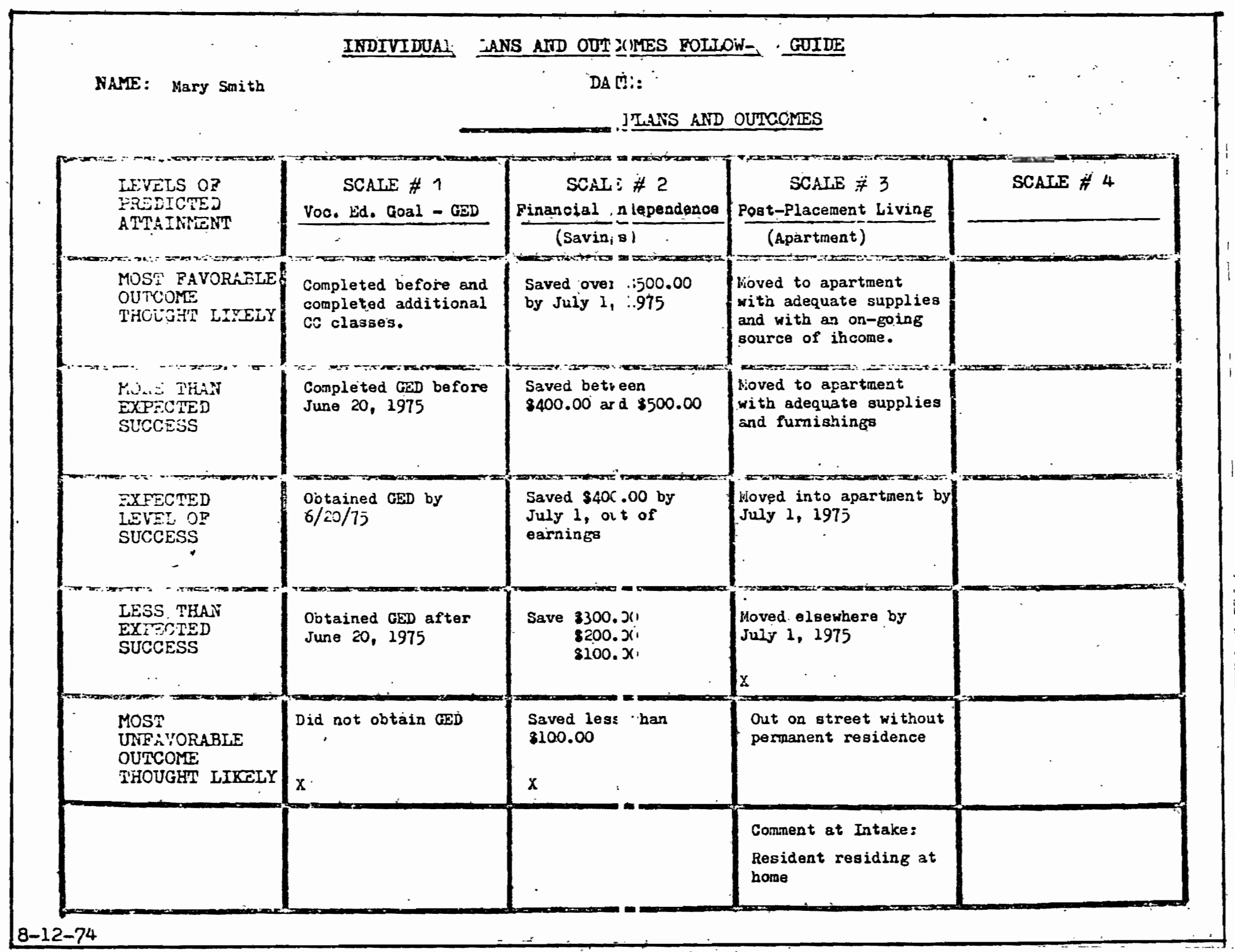

Figure 3. Sample Individual Plans and Outcomes Follow-Up Guide 


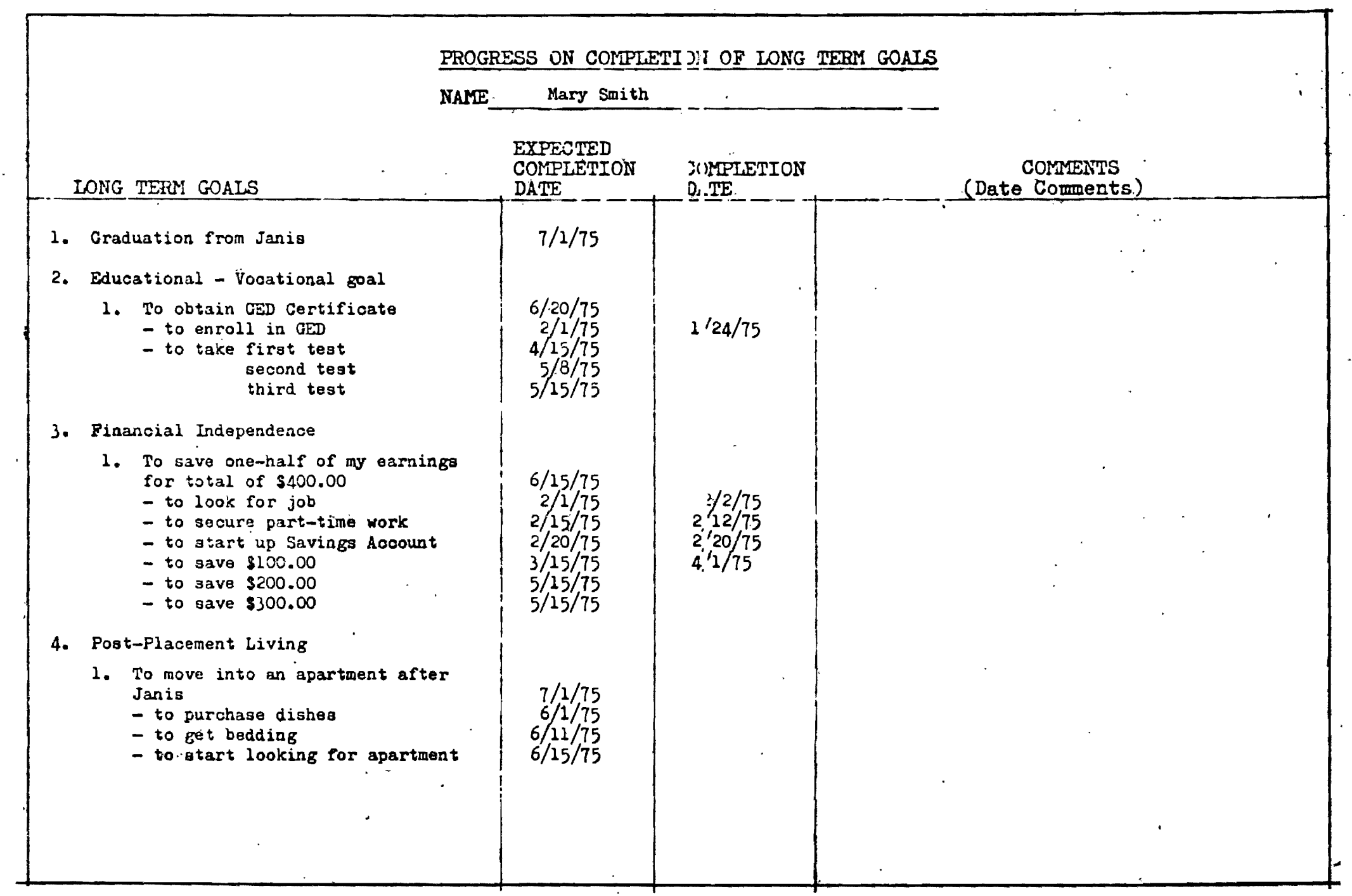

Figure 4. A sample: Progress on Completion of long-term goals form. 
afternoon. The resident meets with a member of the house staff and completes the Mutual Planning Form (Figure 5.). This form is subdivided into 4 areas reflecting three program goal areas and one area for persional goals. The form is columned into two parts. The left side is the goal in the broadest phrasing. This is used for scale heading. On the right is the commitment that the resident makes for the week toward his goal.

It is the Mutual Planning commitment that becomes the basis for the IPO. The IPO follow-up guide constmaction takes place in midweek as the house parents have time. The follow-up guide is constructed based on the constmaction guide (Appendix B) and the needs of the resident. The resident's planned commitment, transfers to the expected level of outcome as in the long-term IPO. It is orucial that the reaident receive staff help in phrasing his commitment in specific behavioral terms. After completing the expected level of outcome on the IPO, the staff member completes the most favorable and most unfavorable levels, with the intermediate levels completed last.

The completed follow-up guide is then held for outcome measurement. This is done on the following Sunday as part of the next Mutual Planning conference. Performance data is obtained from the resident. The IPO is marked and shared with the resident providing reality feedback on his behaviors.

The weekly follow-up guides are not marked for intake level of functioning. They are not being used to measure change, but to reflect the degree of achievement on the residents goal. The attainment scores used on weekly follow-up guide is the numerical value assigned 
to the scale level which reflects the resident's behavior. The scores range from +1 to +5 reflecting the scales levels from most unfavorable to most favorable outcomes. The resident who attains the expected level of outcome scores $a+3$. The scoring process was refined after five weeks of usage to allow for subdivision of levels so that we, in effect, have fractional attainment scores. The use of this subdivision is illustrated in Figure 5 .

\begin{tabular}{|l|l|}
\hline $\begin{array}{l}\text { Expected level } \\
\text { of success }\end{array}$ & Attended four days \\
\hline $\begin{array}{l}\text { Less thai } \\
\text { expected level } \\
\text { of success }\end{array}$ & $\begin{array}{l}\text { Attended 3 days } \\
\text { Attended 2 days } \\
\text { Attended 1 day }\end{array}$ \\
\hline $\begin{array}{l}\text { Most unfavorable } \\
\text { outcome thought } \\
\text { likely }\end{array}$ & Did not attend \\
\hline
\end{tabular}

Figure 5. Partial scale illustrating use of subdivision of a level.

The less than expected level is subdivided into three behavior outcomes to refleot more specific performance of the resident. The scoring of the subdivision is done by assigning fractional values to the behavior outcomes. The values would be as follows: attended three days equals 2.5; attended two days, equals 2.0; attended 1 day equals 1.5. The expected level would retain it's numerical value of 3 . The formula or computing subdivision scores is: $2+$ (Number of subdivisions $+1)$. This formula provides the fractional increment between subdivision levels. 
The subdivision process was initiated to provide more specific feedback to the resident's on actual attainment, especially on levels which could cover a wide range of resident behaviors. The use of positive attainment scores rather than the +2 to -2 range of the GAS was interided to further underscore the pasitive focus of the IPO program.

The weekly IPO's are kept in a file for case review. The progress made on weekly attainments is recorded on the "Progress on Completion of Long-Term Goals," Figure 2, by filling in the completion date column on the form.

The system is complex, so to clarify it we have included examples of a Mutual Planning form and the IPO Follow-up Guide generated from it. The examples are not from a particular resident but are composites ealling on features common to many of the forms complete at the Hawthorne House. These examples are based on the long-term goals developed in the previous section. The continuity of the sections. is to illustrate the connection between long-term and weekly IPO's.

\section{Monthly Case Review}

The monthly case review provides the integration of the long-term and the weekly IPO systems. The function of the monthly case review is to assess the progress and problems of the resident. The weekly IPO's and Progress form are used to help assess the residents progress toward his long-term goals. It is at this meeting that residents can reassess their long-range goals and modifications or substitutions can be made if it is agreeable to all parties. If the resident is consistently behind his time line or is not complying with other commitments that 
MUTUAL PLAIIIING

RAME: Nary Enith 'NEEK DATED

THIS WTEKS GONLS

Sk11I Devel opment

Educational Goal - H Study G:D

Educational Goal - \#2 GED test

Vocational Goal - \#1

Vocational Goal - \#2

RUTUAL PLANHEW COBHITHTHCNTS

(Include lays and Hours)

\#I I will zo to Gidl clasges Tueday and Thuradiay - 1:00 to 4:30 p.m.

12 I will take my Math test rhursday, April 10, at 1:00 p.m.

41

$\$ 2$

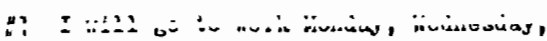
$\$ 2$ Friday - 9:00 a.m. to 5:00 p.m.

Employment Goa] - 2

1

$\$ 2$

Post Placement Living Goa 1 " 2

Personal (jrowtl

Pérsonal Goal $\# 1$

Personal Gual th

Viuit ramily

Il I will visit with my family on

Personal Goal H3 


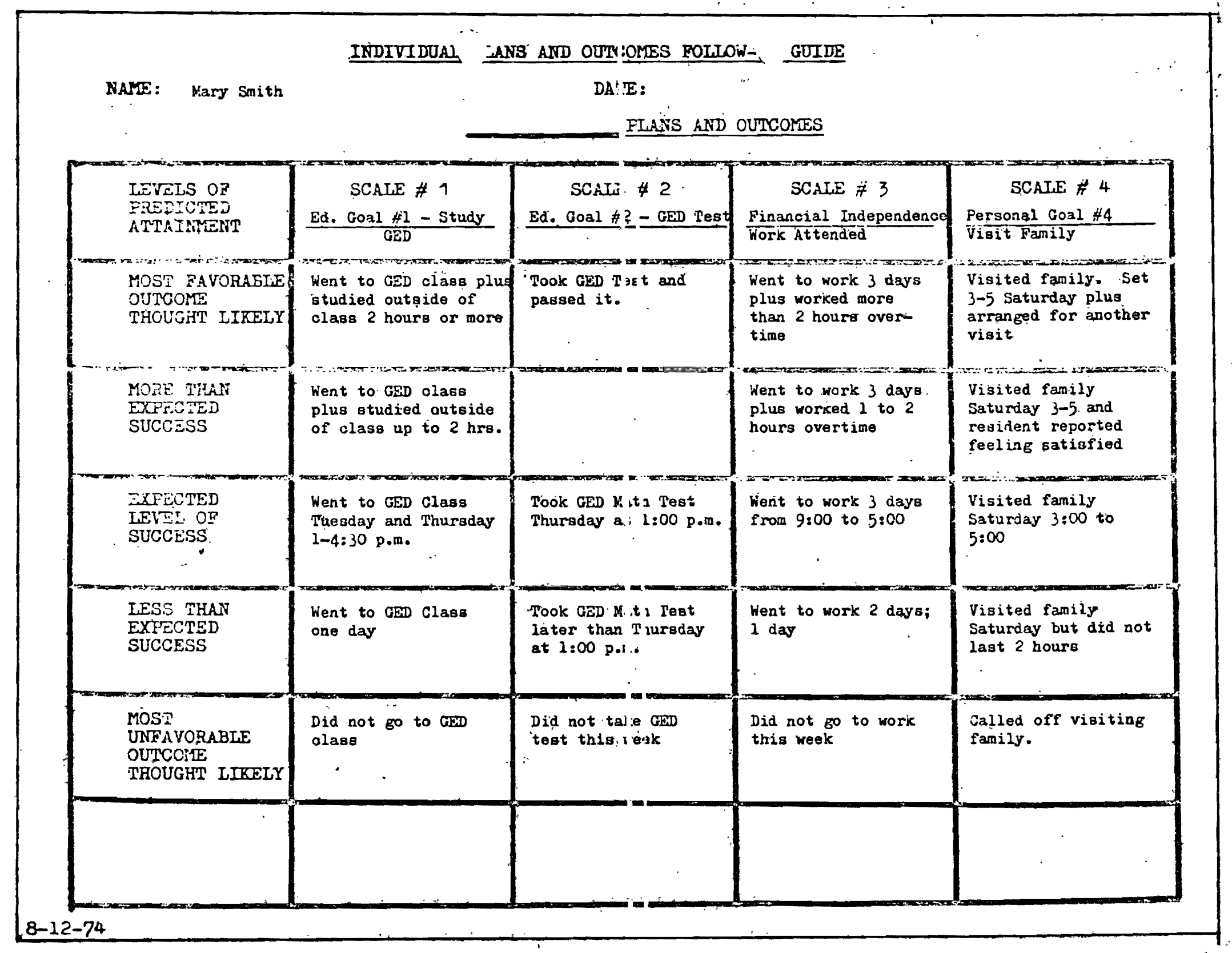

Figure 7. A Sample weekly IPO follow-up guide. 
he has made, he may be given consequences or even dropped from the program.

Summary:

The IPO system is the expansion of Goal Attainment Scaling into a complex treatment, progress-monitoring system. It involves many modifications on GAS as it has been used in Nental Health clinics. It retains the value of measuring attainment at five different levels rather than just a pass-fail system. It involves the resident and house staff in mutual goal setting toward goals that are relevent to the resident. 
CHAPTER V

USE OF SCALE ASSESSMENT TO IMPROVE SCALE QUALITY

One of the key skills in using Goal Attainment Scaling is the ability to scale goals effectively. In the Janis IPO program this remains true. Quality scaling is necessary both for accurately measuring the residents behavior and in providing meaningful feedback to the resident.

In order to improve and standardize the quality of scales constructed by the Hawthorne House staff, two processes were utilized. First a brief manual for construction was developed. This is the "Guide to Scale Construction" (Appendix B). The second was to utilize a scale assessment system for training in the technical features of scale development. It is this scale assessment system that is presented in this chapter.

The scale assessment system was selected as the training tool for several reasons. It was an already existing tool employed by the Program Evaluation Project staff. The reliability and utility of the tool had been adequately tested. The tool was modifiable for use in Janis. The assessment system, further, contains a built-in measurement system to assess progress.

The assessment system evaluates the scales on the weekly IPO's after they are constructed. Feedback can then be provided to the house parents so that they improve on problem areas in their scale construction. 


\section{BACKGROUND ON GOAL ATTA INMENT SCALE' ASSESSMENT SYSTEM}

The scale assessment system used for the Hawthorne House project is based on the GAS assessment system outlined in "Preliminary Working Paper on the Manual for the Standardized Assessment of the Goal Attainment Follow-Up Guide," by Garwick and others. The foundation and utility of this system is described in the above publication and will not be fully discussed here. Briefly the process involves the steps indicated in Figure 8.

The scale construction is done by an intake level mental health practitioner who establishes both goal and scales after an intake interview with the client. The follow-up guide is then assessed by two research staff members based on an extensive system of point deductions for specific problematic features. The two independent assessments are then collated, i.e., the point deductions are averaged to produce a single assessment form covering each follow-up guide. The collated score is compared to an established score for acceptability. If the collated score falls below this level, the form is returned to the constructor for negotiation on the problematic features. Not all violations need be corrected. In some cases considerations are made for special clinical circumstances that demand special scale construction; which, if adequately explained, do not draw any point deductions. After negotiation the score is reassessed and sent to follow-up or scrapped if it is still unacceptable.

If the collated score falls above the cut-off level, the guide is sent to storage until the follow-up date. Follow-up is conducted 
Construction

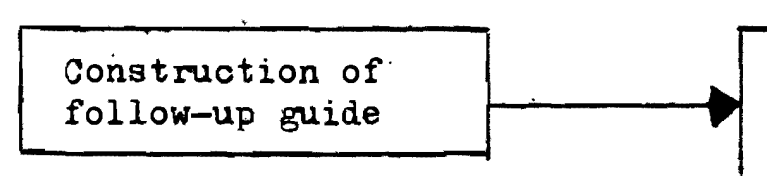

independently review

and assess guide

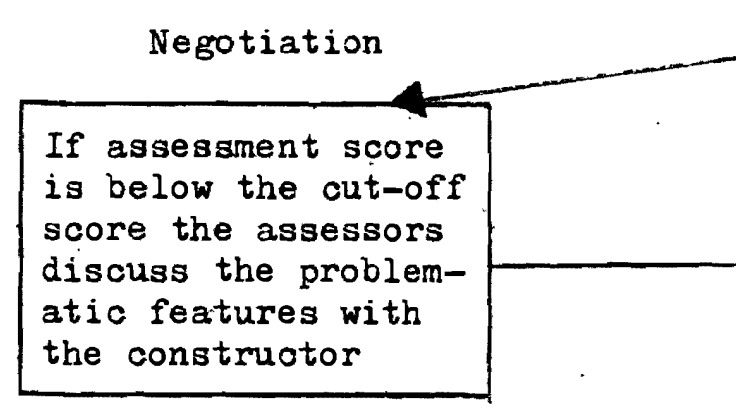

atic features with

the construotor
Reassessment

After negotiation and
constructors improve-
ments, the point
deductions should be
reassessed to
determine if the
changes raised the
score above cut-off
Rejection
If score is still
below cut-off, scale,
is scrapped

Collation

Two assessments are averaged on a single assessment form

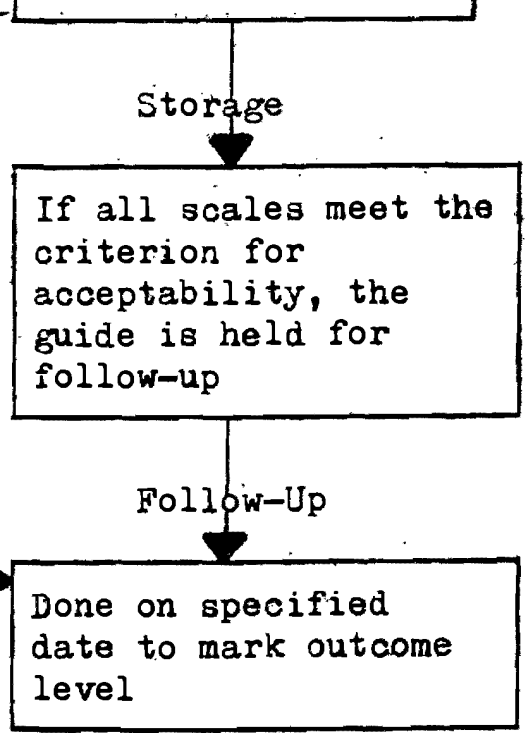

Figure 8. Goal attainment assessment system. 
by additional research personnel to determine outcome level

for the client.

For more information on the Goal Attainment Scaling Assessment, we refer you to the above mentioned publication.

\section{THE JANIS ASSESSMENT SYSTEM}

The GAS scale assessment system was modified to meet the specific needs of the Janis Program. These needs are outlined in Chapter IV and in the "Scale Construction Guide." The modifications were made in the assessment process and in the assessment instrument.

In the assessment process the deviation from the GAS system occurs after collation. Because the focus is on training as well as evaluation, the IPO's are not scored against a minimum acceptability criterion but rather are scored and then reviewed by house parents. Negotiation does take place if some of the point deductions are disputed by the constructor. The score can be modified in this way before the scale goes to follow-up. No scales are actually rejected in this system. On the short-term IPO's, follow-up usually occurs one week after construction. Follow-up is done by the same worker who constructs the scale, which again differs from the GAS system.

In the instrument the modifications include the elimination of four of the problematic features used in the original GAS soheme. They were eliminated because they were not applicable because of modifications in the program. Included in the deletions were the following features which were considered problematic: 1) Only some scales weighted; 2) Should comment be typed on Euide; 3) Is mention of level 
at intake necessary; 4) Date implied contradicts follow-up date. Seven items were added to the list beoause of specific requirements of the Program. These seven items are problematic features "O" through "U" in the point deduction system. These modifications do not alter the basic design or effect the validity of the instrument or the process. The modified point deduction system, as it was used, is included as Appendix C, "Description of Catagories of Problematic Features and the Recommended Point Deduction Associated with Each Catagory." The "Description" is a listing of specific problems that interfere with the effective use of the scale at follow-up. The point deductions reflect the degree to which the problem interferes with follow-up. Assessment is the process of establishing a score for each scale based on whether one or more of the problematic features listed appear in the scale.

\section{THE USE OF THE IPO ASSESSMENT FORM}

The following, Figures 9 and 10, are the front and back respectfully of the modified assessment form. The modifications include changes in the specific problematic features discussed in the previous section which are listed on the front page left column along with the corresponding letter code. The second modification is the reduction of the number of scales from five to four to correspond to the Janis IPO form. The third modification is the addition of the comment section on the back (Figure 10). The latter was particularly important due to the training focus. This space allows for positive comments on good features, and allows for suggestions to improve the scale. 


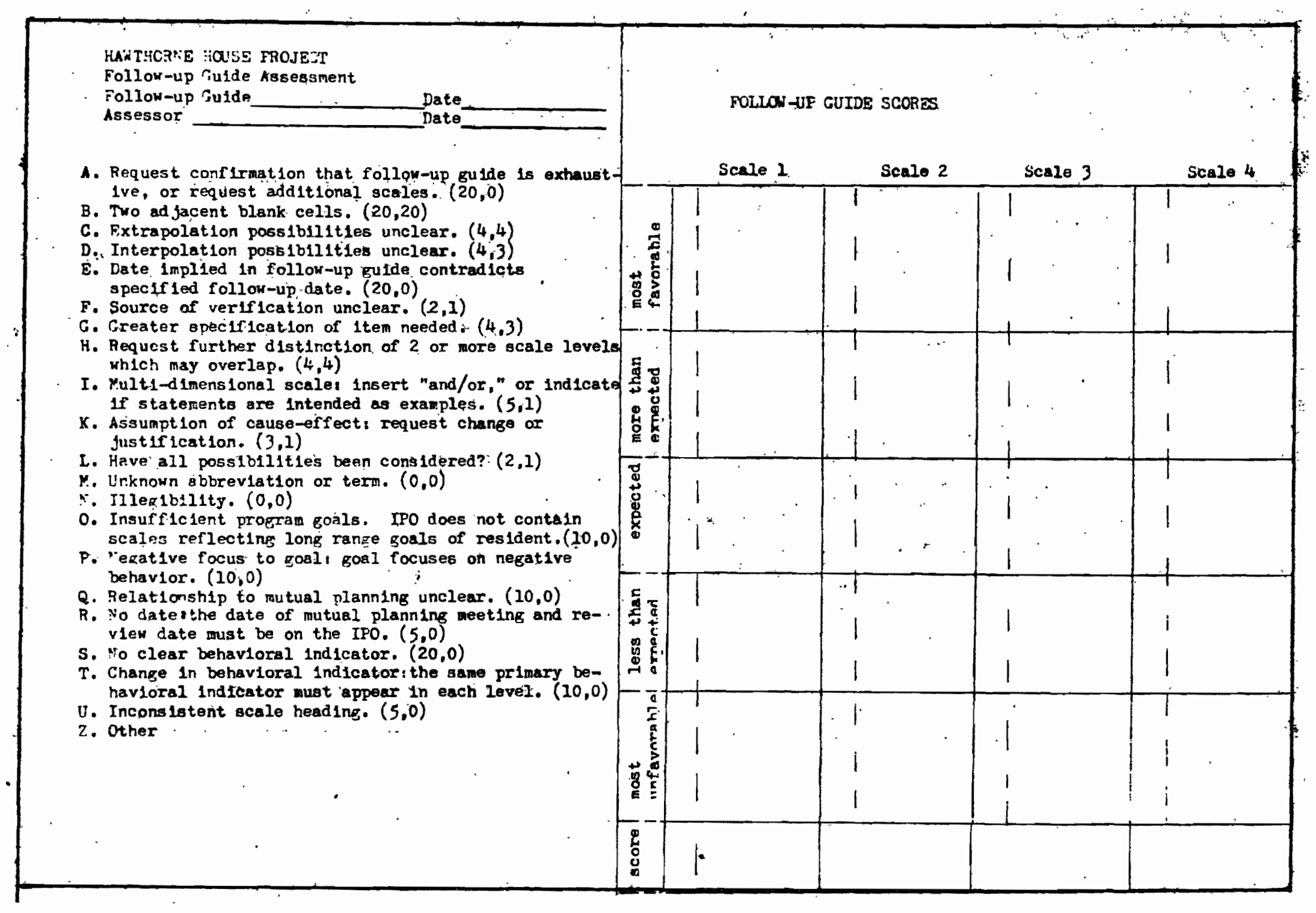

Figure 9. The face section of the IPO scale assessment form. 

The right half of Figure 9 is the assessment grid which corresponds to the four scales on the IPO. The grid depicts the five possible levels of each scale. Each box, representing an individual outcome level, has a dotted line dividing it in two. The portion to the left is used to list the letter indicating a specific problematic feature in that level of the corresponding scale. The area to the right is used to describe the problematic feature, and the point deduction for that feature. The point deductions are then added together. The sum is subtracted from twenty to give the scale score which shows up at the bottion of the scale. Additional comments are made in the corresponding box on the back.

To illustrate the use of the scale assẹssment system, we have developed a sample IPO follow-up guide (Figure 11), and provided a fallow-up guide assessment (Figures 12 and 13) of that IPO. The assessment form contains a listing of titles of the problematic features, and the letter designation for the feature.

This example is not intended to answer all questions about the assessment process. It is intended to illustrate the basic features. The problematic features found on this sample IPO won't be dealt with in the text. The letter designations of the problems appear on the front of the form on the grid space corresponding to the scale and the level where the problem appears on the IPO. The problematic feature can be best understood by referring to comment seotion of the form (Figure 13), and the descriptions in Appendix C. 


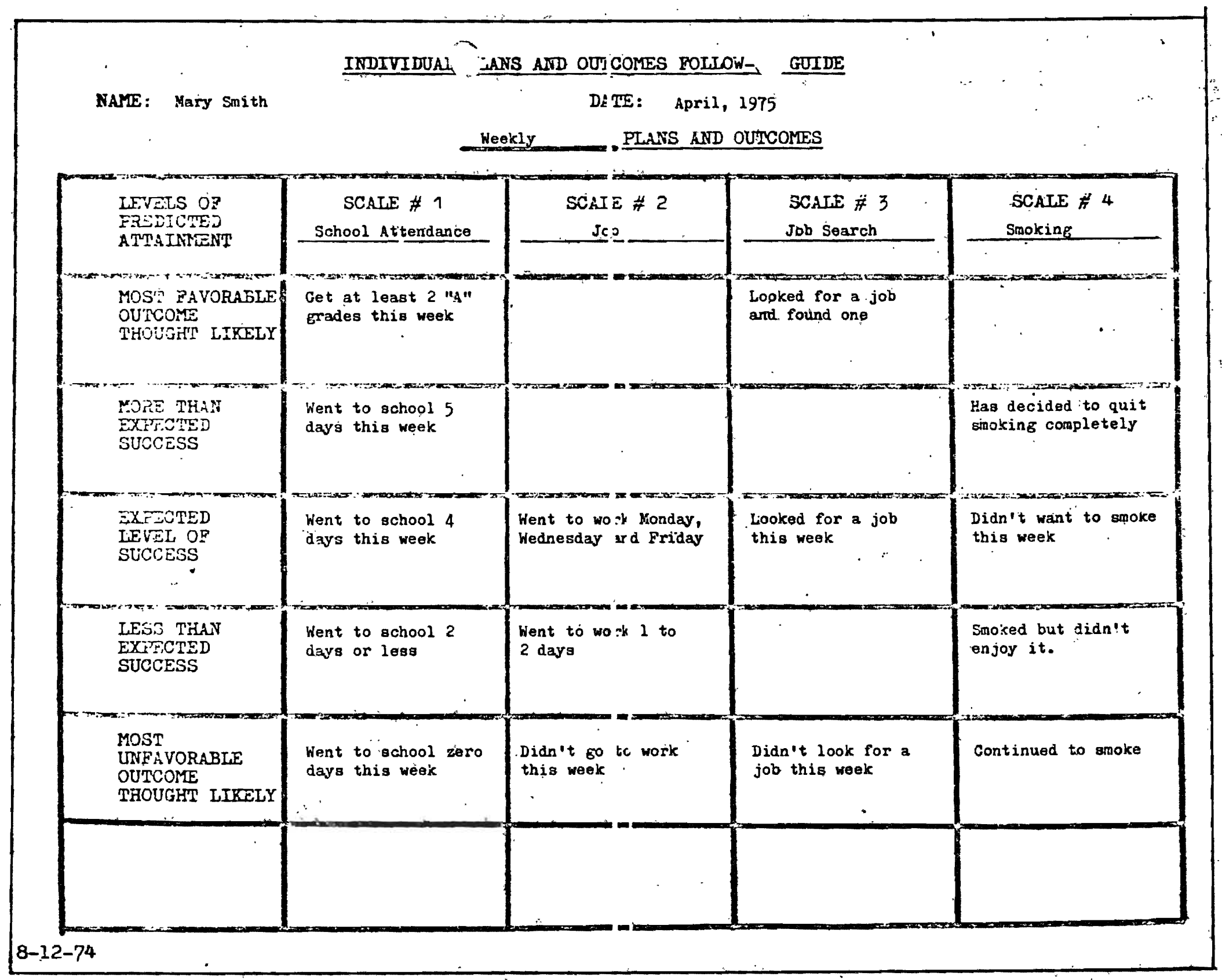

Figure 11. A sample problematic IPO- follow-up guide. 


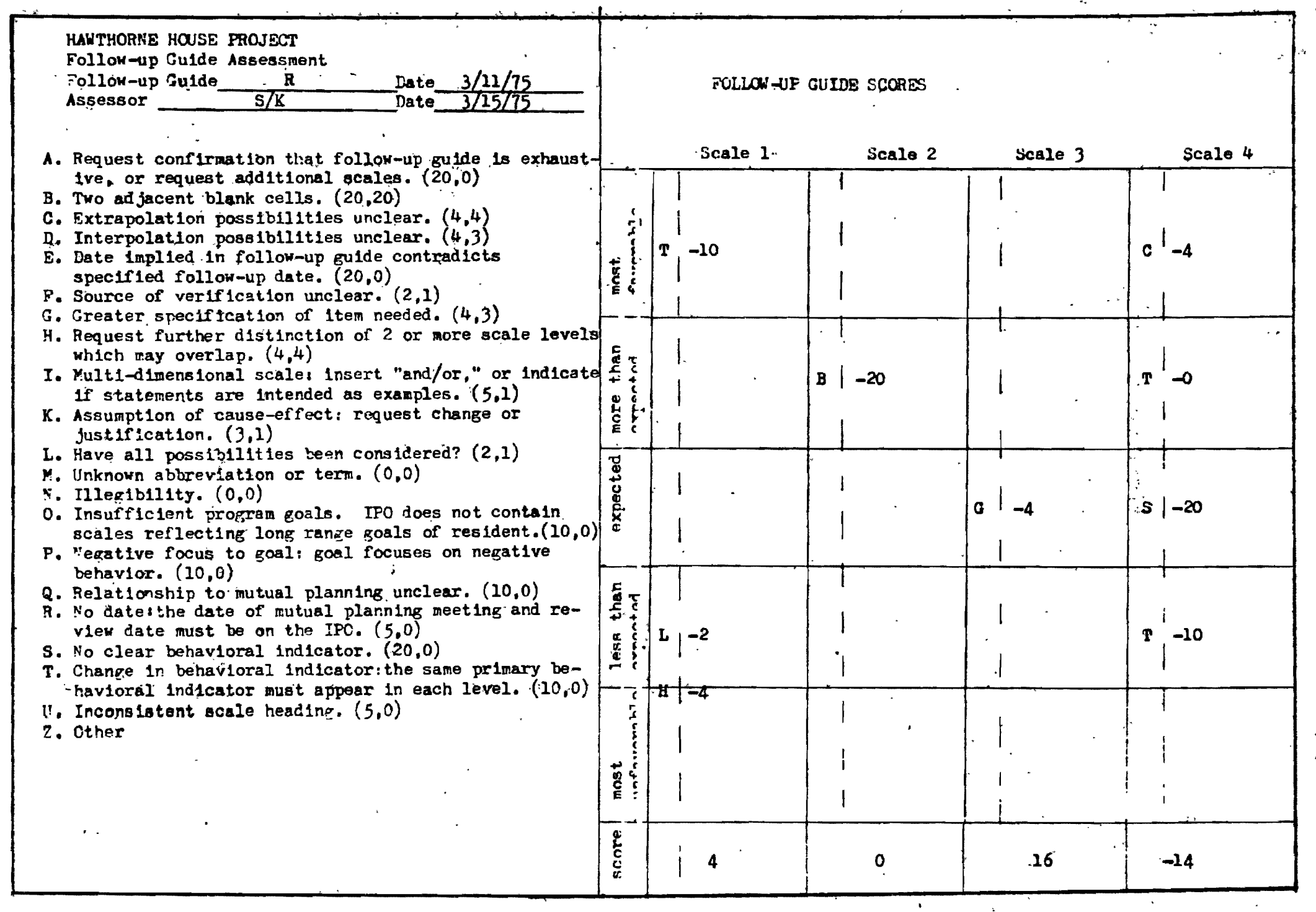

Figure 12. Face section of a sample follow-up guide scale 


\begin{tabular}{|c|c|c|c|}
\hline$\cdot$ & TOLWO:-LIF SUIDE COFAENTS & & \\
\hline SCALE 1 & SCALS 2 & SCRLE 3 & SCALE 4 \\
\hline $\begin{array}{l}\text { Change in indicators from } \\
\text { attendence to performance. } \\
\text { Suggest carrying attendence } \\
\text { through all levels then } \\
\text { adding performance at this } \\
\text { level as a second indicator, } \\
\text { or using a geparate scale } \\
\text { for performanoe. }\end{array}$ & . & $\cdot$ & $\begin{array}{l}\text { The most favorable outoome } \\
\text { does not appear. If deciding } \\
\text { to quit is the most farorable } \\
\text { outcoms, it ihould be moved } \\
\text { to this level. Level } 5 \\
\text { ahould be completed before } \\
\text { level } 4 .\end{array}$ \\
\hline . & $\begin{array}{l}\text { Two adjacent blaink levels; } \\
\text { confirmation needed that workin } \\
\text { three days is as muah as the } \\
\text { resident oan or should do. }\end{array}$ & $\cdot$ & 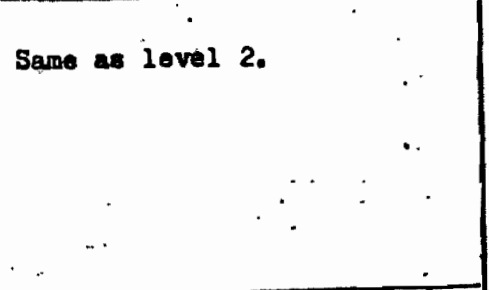 \\
\hline . &. & $\begin{array}{l}\text { The behaviors that the reai- } \\
\text { lent is to use in looking for } \\
\text { i job should be epecified, } \\
\text { such as going to the employment } \\
\text { iffice, nanpower office, gaing } \\
\text { in oertain number of interviews, } \\
\text { itc. }\end{array}$ & $\begin{array}{l}\text { No behavioral indigator. } \\
\text { "wanting" is not a behavior. } \\
\text { Suggest using number of } \\
\text { oigarettes or other objective } \\
\text { indicators. }\end{array}$ \\
\hline $\begin{array}{l}\text { The posaibility of } 3 \text { days } \\
\text { attendance is not oovered } \\
\text { in this level or tha level } \\
\text { above. } \\
\text {... }\end{array}$ & . & ' & $\begin{array}{l}\text { The indicator is vagie and } \\
\text { aloo changes from the expecte } \\
\text { level. There is no indieator } \\
\text { that appears at all levels. }\end{array}$ \\
\hline $\begin{array}{l}\text { These two levels overlap } \\
\text { since "zero days" is "less } \\
\text { than } 2 \text { days." Suggest using } \\
\text { "l to } 3 \text { days" at lese than } \\
\text { expeoted level and "zero } \\
\text { days" at this level. }\end{array}$ & . & & . \\
\hline
\end{tabular}




\section{CHAPTER VI}

\section{EVALUATION OF SCALE ASSESSMENT}

The goal of our assessment system has been to improve and standardize the quality of scales constructed by the Hawthorne House staff. In order to determine whether this goal was reached, an ongoing evaluative component was employed. The evaluation was based on the assessment scores of the scales constructed. The scores were monitored over an eleven week period of time from January 12, to Maroh 30, to determine whether there were any trends in the scores. The evaluation of the data on scale assessment will be dealt with in Sections II and III in this chapter. Section II looks at the deta on collated assessment scores for trends during the eleven week evaluation. Section III deals with the collation process by looking at the agreement in scoring between the two independent assessors. The research process is outlined in both sections and the findings are discussed.

\section{EVALUATION OF SCALE ASSESSMENT DATA}

The goal of scale assersment is to provide feedback to the staff on specific problematic features which appear in the IPO's in order to help the staff avoid those problems and therefore, produoe better scales. The indicators for the goal are: 1) increase in the assessment scores during the assessment period; 2) reduction in the number of 
epectfic problematic features appearing in the weekly IPO's during the assessment period.

To achieve the goal, data was collected on a weekly basis on the collated assessment scores for each scale of the five residents followed. The mean weekly assessment ocores were then compared graphically for changes and trends over the eleven week period. Then data was,colleoted on the specific problematic features which were found. This data was tabulated and analyzed for trends which occur during the assessment period.

Table II is the tabulation of mean collated assessment scores each week for each resident. Within the Table, resident identifioation $A, B, C, D$, and $E$, are the letter designations for the individual residents followed in the IPO program. The "Date of IPO" indicates the date on the scale being assessed. The scores indicated are the mean collated scores for the week. The "mean" is the overall mean for the resident. The group scores indicate the mean score for the five residents.

The data from the table indicates very little difference in the resident mean assessment scores. The scores range from 17.6 to 18.9 for the five residents followed for the entire time. From this data the assessment scores would not appear to be a function of the resident's personality or situation.

The individual soale assessment scores vary from 5 to 20 . When plotted out as weekly mean scores for each resident, Figure 14, they show considerable fluctuation with little in the way of trend except that the last three weeks show consistent, high scores. When plotted 
TABLE II

WEEKLY ASSESSMENT SCORES. FOR RESIDENTS

\begin{tabular}{|c|c|c|c|c|c|c|c|c|c|c|c|c|}
\hline \multirow[t]{2}{*}{ Resident } & \multicolumn{11}{|c|}{ Date of IPO } & \multirow[t]{2}{*}{ Mean } \\
\hline & $1 / 12$ & $1 / 19$ & $1 / 25$ & $2 / 2$ & $2 / 9$ & $2 / 16$ & $2 / 23$ & $3 / 2$ & $3 / 9$ & $3 / 16$ & $3 / 23$ & \\
\hline \multicolumn{13}{|l|}{. } \\
\hline$A$ & 18.5 & 16.3 & 15.3 & 20 & * & 20 & 20 & 17 & 20 & 20 & 20 & 18.9 \\
\hline$B$ & 11 & 18 & 14.5 & 15 & 18.3 & 18.3 & 17.5 & 20 & 20 & 20 & * & 17.6 \\
\hline$c$ & 13 & 16.8 & 16.5 & 20 & 19.8 & 19.7 & 16.8 & 19.4 & 20 & 20 & 20 & 18.4 \\
\hline$D$ & 11 & 16.5 & 19 & 16.7 & 19.3 & 18.1 & 18.5 & 19.8 & 19.7 & 20 & 18.5 & 18.0 \\
\hline $\mathbf{E}$ & 14.3 & 19.2 & 18.2 & 15 & 20 & 20 & 19.8 & 19.8 & $17 \cdot 3$ & 19.5 & 19.3 & 18.6 \\
\hline Group & 13.6 & $17 \cdot 3$ & 16.0 & 18.0 & 19.4 & 19.2 & 18.8 & 19.5 & 19.3 & 19.9 & 19.4 & 18.3 \\
\hline
\end{tabular}

* Assessment Score not available 
by weekly group mean scores, which more accurately reflect the weekly skills of the staff in scale construction, there is a more pronounced trend. The scores mun from 13.58 to 19.89 . There is a substantial trend toward increased assessment scores with the passage of time. This trend shows itself on the graphical profile for the group. The scores level off after the seventh week at a mean score of 19.33 or higher. These high scores indicate near-perfect scale construction. (See Figure 14).

The data on frequency of problematic features indicates a similar trend. In Table III the data is tabulated showing the frequency with which each problematic feature occurs. The problematic features are indicated by the letter designation employed in the assessment process. The letters not appearing indicate that the feature did not show up on the weekIy IPO's during the study. The marginals at the right are totels for each problematic feature found indioating the total number of times it appeared. The bottom marginals indicate the tatal number of problematio features or errors for each week and the number of scales used by the staff during the week. The number of errors per scale are then computed for each week.

This data indicates that the number of errors per scale decreases over time from a high of 1.3 errors per scale on the first week, to low of 0.11 errors per soale on March 16, the tenth week, then a slight inorease to 0.50 on the last week of assessment. Interestingly, the number of scales used by the staff and residents increases steadily during the assessment period until the last week.

Looking at speoific problematic features, the frequently occuring 


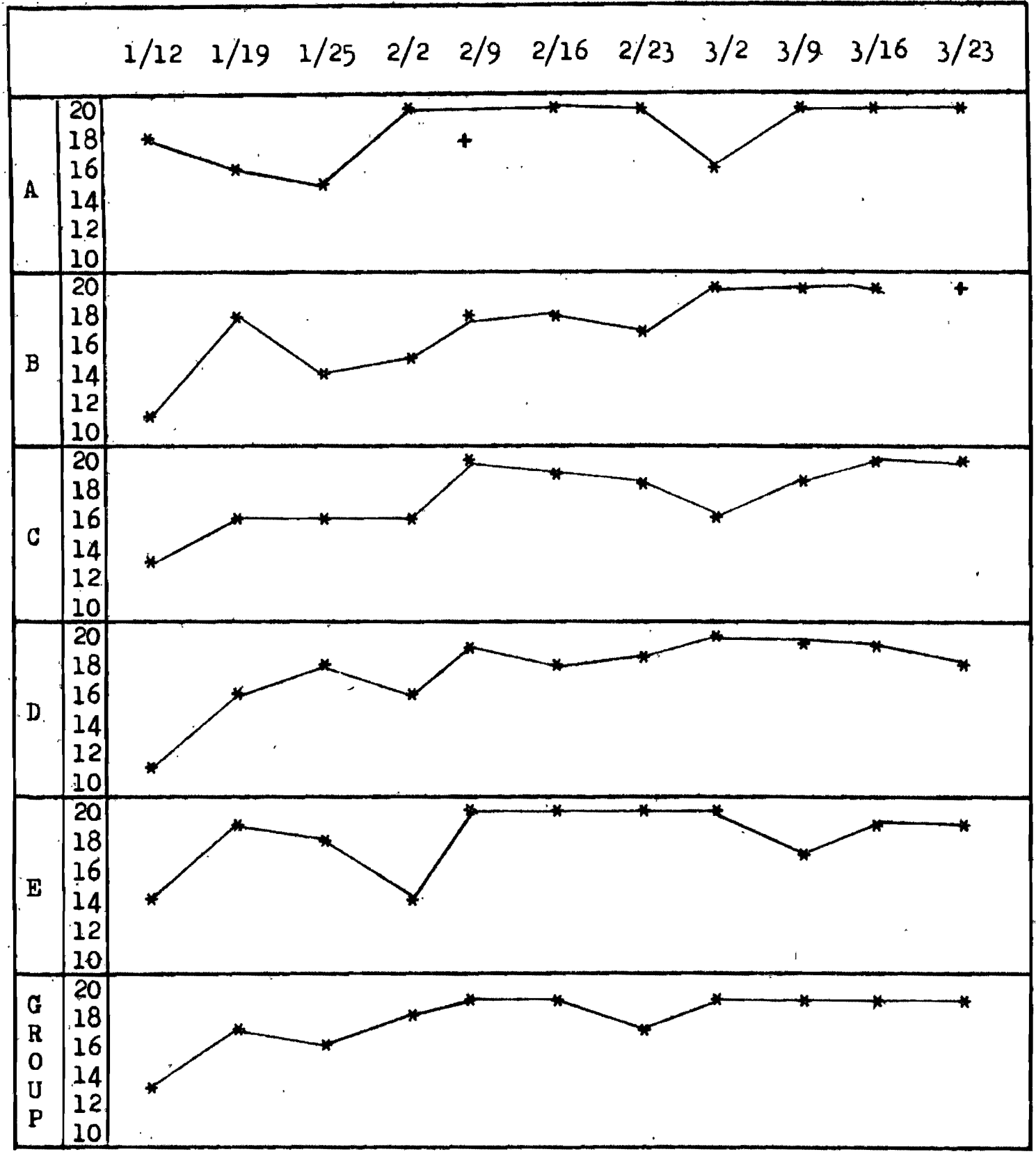

Figure 14. Graphic profile of assessment scores

+ Assessment scores not available 
TABLE III

FREQUENCY OF OCCURRENCE OF PROBLEMATIC FEATURES

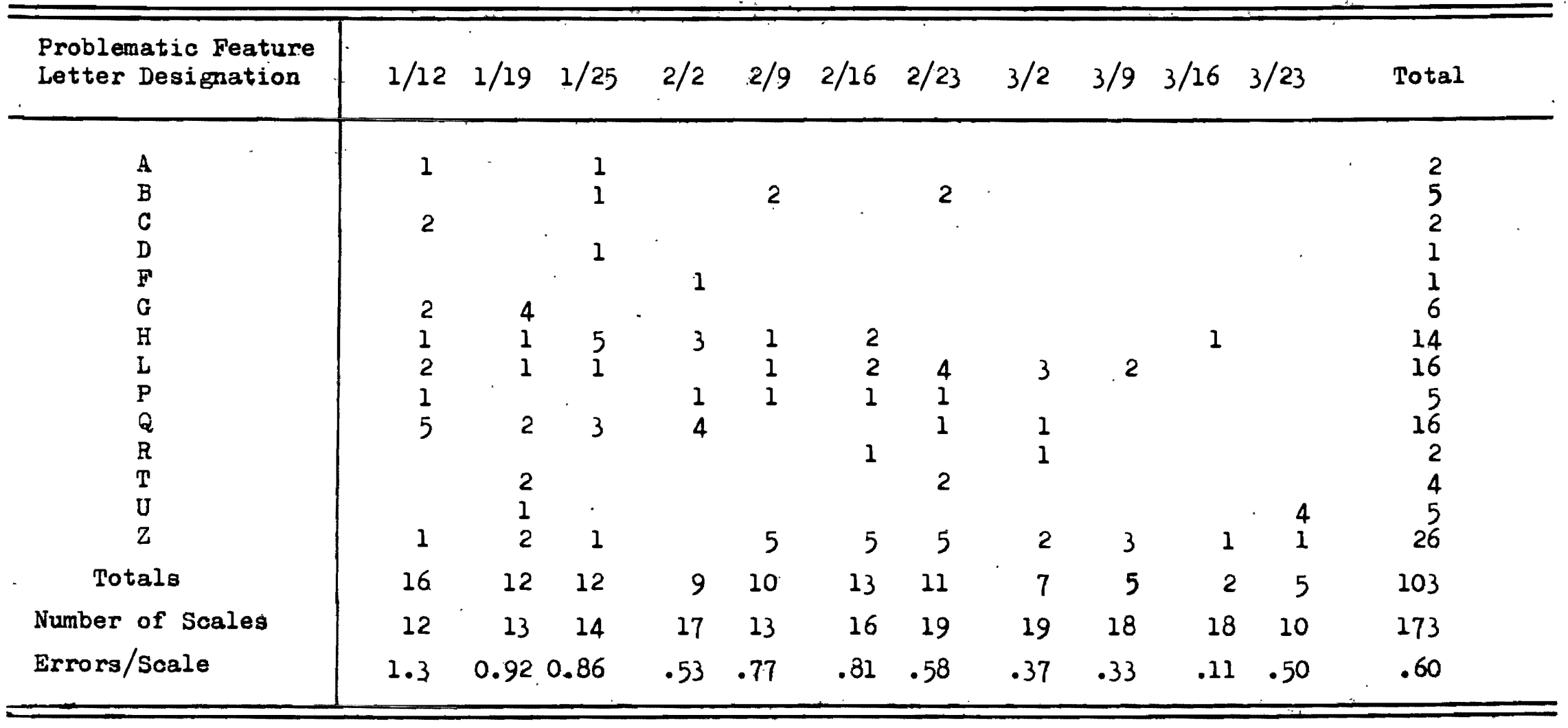


features are item "H", "L", "Q", and "Z": Of these features "H" and "Q" show a marked decrease midway through the assessment period. Both of these are major problematic features; " $Q$ " reflects a problem in the transition from mutual planning to the IPO scale, "H" refers to overlap between adjacent levels which make the scale hard to use at follow-up. The remaining two features appearing most frequently are "Z" and "L". Item "Z" is a catch-all catagory used for less severe problems and suggestions. Item " $L "$ is important but not severe, as it refers to "Not covering all possibilities" in the scale which is an exeroige in oreativity more than technical competence. Based on our data, the goal of producing better scales has been met. The assessment scores demonstrate a consistent and substantial increase during the assessment period. At the same time the number of problematic features decrease with the passage of time. These two indicators are related, but because of the wide range of point deductions for various problematic features, both indicators are needed to show the quantity and quality of improvement encountered.

\section{EVALUATION OF THE COLLATION PROCESS}

The use of two independent assessors employed by the Program Evaluation Project was an attempt to maintain a measure of reliability in the assessment scores. The same process was employed in the Hawthorno House Project. Beoause the extensive research staff used by P.E.P. was not available to this project, quantitative evaluation of reliability is not possible. The use of the collation process did allow for qualitative evaluation of the scores by. comparing the scores of the two independent assessors. 
This comparison process involved data collection on the soores of both assessors for each scale assessed. The scores for eaoh wesk were then converted to mean scores for each assessor for the week. The mean scores were compared to determine the amount of disagreement for the week.

The data obtained is tabulated in Table IV; "Scoring Differences Between the Two Independent Assessors by the Week." The table shows the mean scores for the two assessors for each of the eleven weeks. The numerical difference between the scores is then shown in the last column.

TABLE IV

SCORING DIFFERENCES BETWEEN THE TWO INDEPENDENT ASSESSORS BY THE WEEK

\begin{tabular}{cccc}
\hline \multirow{2}{*}{ Date of IPO } & \multicolumn{3}{c}{ Mean Weekly Scores } \\
\hline \multicolumn{1}{c}{ Assessors } & Assessors & Difference \\
\hline 12 & 12.3 & 14.8 & 2.5 \\
$1 / 19$ & 16.9 & 17.7 & 0.8 \\
$1 / 25$ & 17.6 & 14.3 & 3.3 \\
$2 / 2$ & 18.7 & 17.3 & 1.4 \\
$2 / 9$ & 19.2 & 19.5 & 0.3 \\
$2 / 16$ & 19.0 & 19.2 & 0.2 \\
$2 / 23$ & 19.5 & 18.0 & 1.5 \\
$3 / 2$ & 19.1 & 19.5 & 0.4 \\
$3 / 9$ & 18.9 & 19.8 & 0.9 \\
$3 / 16$ & 20.0 & 19.8 & 0.2 \\
$3 / 23$ & 18.8 & 20.0 & 1.2 \\
\hline
\end{tabular}

The data indicates considerable consistency in the scoring except 
for the first and third weeks. The remainder of the time the point difference is below 1.5. The range is from 1.5 on February 23, down to 0.2 on February 16 and March 16. The number of scales assessed after the third week increases steadily (Table III) so that there is a trend toward closer agreement on scores on an increasing number of scales.

Counter balancing the indication of a higher degree of agreement in assessor scores is the higher attainment scores. There are fewer problematic features encountered in the last seven weeks so there are fewer items to disagree on. Given this, the overall trend is that both independent assessors judged the scales as having higher assessment scores with a low degree of disagreement between them.

III. SUMMARY

The use of scale assessment as a training tool in scale development has shown positive results. The data illustrates improvement in scale quality. There are other equally important skill advancements which are outside the scope of the objective data. One such gain was the staffs willingness to soale ever more difficult items. Particularly in the last four weeks of assessment the percentage of personal growth goals increased, and likewise the number of scales reflecting performance measurements rather than just attendance measurement increased. Much of the progress in scale quality has to be attributed to the resident's coordinators' willingness to accept criticism and recommendations. This feedback was not only in terms of the written scale assessment, but also in biweekly conferenoes between the 
researchers and the house staff to go over the recurring problematic features, and to go over questions that the researchers or house staff had.

The operation of this type of training system relies heavily on motivated staff who want to use the system, and/or, open communioations between researohers and staff. 


\section{CHAPTER VII}

\section{PROGRAM EVALUATION}

One of the strengths of the IPO system is the built-in evaluative usage. The attainment scores provide a numerical measure of the programs ability to help residents reach their goals. The attainment scores provide hard data on the treatment progress of individual residents, and on evaluation of the overall program functioning. In this Chapter we will look at both areas, treatment progress of individual residents and the overall functioning, that is, program evaluation. Because of the time framework in which data collection took place, the attainment data available is only on the weekly goals. Attainment scores on lang-term goals were not available because of the follow-up dates (oompletion of the program) were not reached by residents during the eleven weekg of data colleotion.

We shall look at the weekly attainment scores on a descriptive basis to see the treatment progress of the individual residents. Then secondly we shall develop a model for using attainment data from the long-term :IPO's for overall program evaluation.

\section{EVALUATION OF DATA ON WEEKLY ATTAINMENT SCORES}

The goal for the evaluation is to provide a descriptive analysis of the attainment profile of each resident. and of the House during the eleven week period of January 12, 1975 through March 30, 1975. This 
analysis includes a desoriptive breakdown of the resident's performance in different goal areas and provides a desoriptive breakdown of the residents general performance over the eleven week period.

In order to meet this goal, data was collected on the attainment scores of each resident on each mutually planned goal. The attainment scores reflect the resident's performance level at follow-up. The scores are computed by assigning numerical values of one to five to the possible outcome levels from most unfavorable to the most favorable levels of outcome. The data is desoriptive data to reflect the attainment of resident goals rather than to measure behavioral change.

\section{Residents' Performance By Goal Area}

The data was analyzed for each resident by the content of the goal. This data was collapsed to look for trends in the programs ability to help residents in various goal areas. Table V "Frequency of Scale Headings Used During the Eleven Week Period," is the tabulation of scale headings used during the assessment period. There were forty-four scale headings used on 135 scales. The frequency with which the scale headings were encountered is indicated following the heading.

This data when compared to the review of scale headings during the September-0ctober period shows a change away from scaling goals on house maintenance and discipline issues. This reflects the increase in resident involvement in goal setting, and the commitment toward focusing on positive behaviors in the goals.

This data on scale headings was collapsed into six goal areas. These areas were selected to reflect both reoccuring themes in the scales and also to reflect the program goal areas within which the goals fall. 


\section{TABLE V}

FREQUENCY OF SCALE HEAD INGS USED

DURING THE ELEVEN WEEK

PERIOD

Job Attendance.

15

GED. Study

Job Search

Work

14

11

Work

Reality Workshop

Volunteer Job Attendance

6

Career Planning

Sohool Attendance

Want Ads

Look for Volunteer Work

6

5

5

4

Paint Sniffing

4

Personal Coal.

Tranoendental Meditation

3

Welding Training

Job Interview

Work Performance

Work Attendance

Manpower

Diet

Anthropology Class

Employment office

Job Satisfaction

Earn Money

2

Letter Writing

other

2

$20 *$

* There were a total of 20 items which appeared only once 
The goal areas and the individual headinge from whioh the areas.

were derived are listed below:

1. IOB related goals-

including job attendanoe, work performance, work attendance, work, volunteer job attendance, job satisfaction.

2. JOB SEARCH related goals-

including job search, employment office, job interview, reality workshop, volunteer work search, want ads, manpower, career planning, resume.

3. EDUCATIONAL-VOCATIONAL related goals-

including CED study, sohool release, school attendance, studying, anthropology class, drama/play, and welding training.

4. POST PLACEMENT LIVING related goalsinoluding cost of living determination, savings transfer and talk with parents.

5. FINANCIAL related goalsincluding savings, money earned, money accounting.

6. PERSONAL goals-

including the following scale headings: reading, learning new words, Dootors appointment, transcendental meditation, smoking dope, diet, personal goal, weight, clothes, house restrictions, return library books, communioation, smoking, paint sniffing.

The attainment data was then tabulated for each resident by goal area (Table VI). The first column in the table is the coding for the residents followed in the program. The next six columns are the goal areas. The last column is the mean attainment score for the resident. Group averages are tabulated at the bottom of the table.

The attainment scores range from 1.0 to 5.0 . The individual residents show considerable fluctuation in goal area scores. Each resident shows strength in different goal areas. This is illustrated 


\section{TABLE VI}

GOAL ATTAINMENT SCORES FOR RESIDENT BY GOAL AREA

\begin{tabular}{|c|c|c|c|c|c|c|c|}
\hline Resident & Job & Job Search & Education/Vocation & $\begin{array}{l}\text { Post } \\
\text { Placement } \\
\text { Living }\end{array}$ & Finanoial & Personal & Mean \\
\hline A & 2.58 & * & 2.60 & 1.00 & 1.00 & 1.77 & 2.22 \\
\hline B & 3.00 & * & 3.0 & * & * & $3 \cdot 50$ & 3.22 \\
\hline C & 3.69 & 3.14 & 2.15 & * & 3.0 & 3.0 & 2.89 \\
\hline D & 2.75 & 2.66 & 3.64 & $*$ & 5.0 & 2.0 & 3.01 \\
\hline $\mathbf{E}$ & 1.94 & 2.09 & 5.0 & 4.0 & * & 2.5 & 2.36 \\
\hline
\end{tabular}

$\mathrm{n}=$ Number of scales

* A.ttainment score not available 


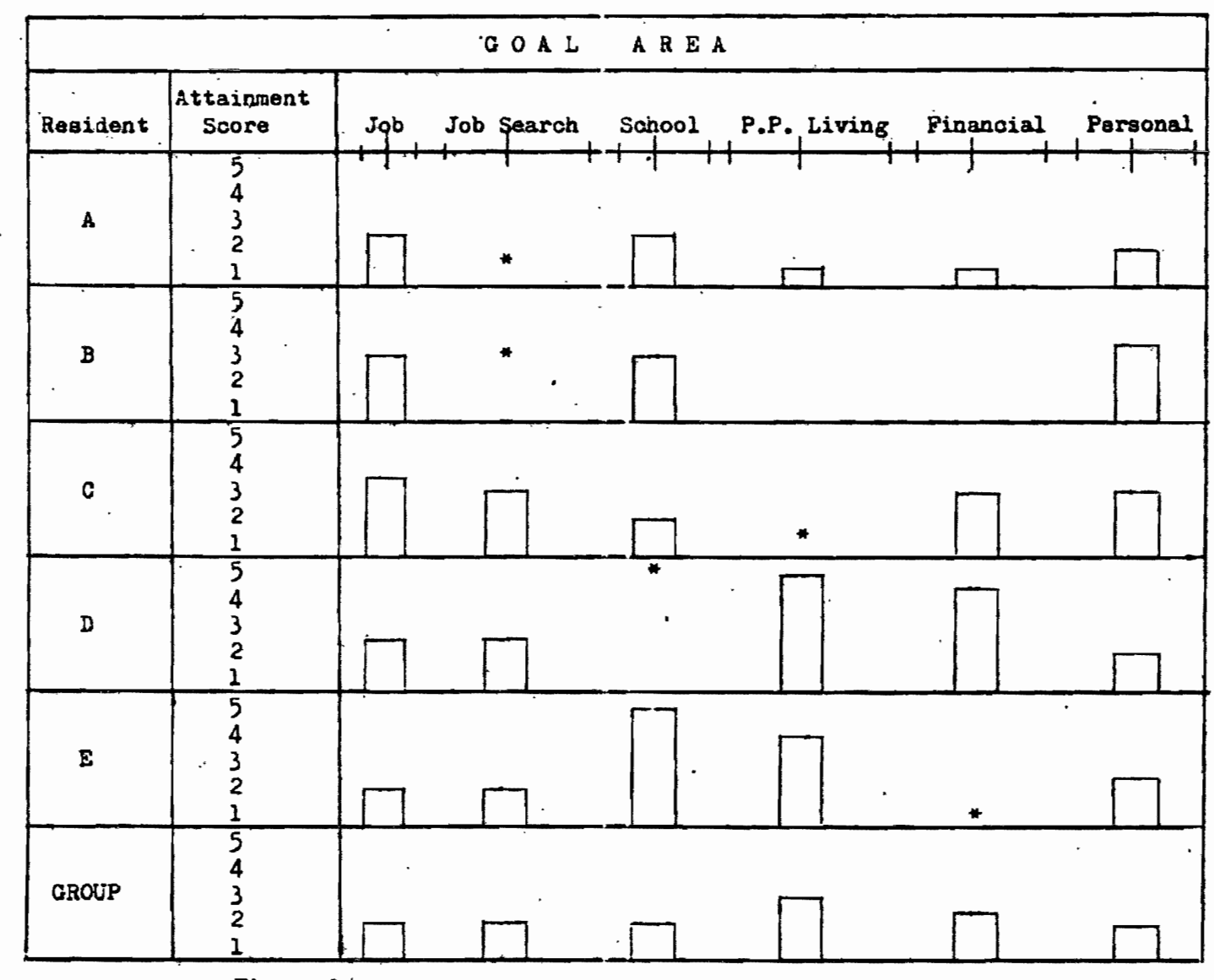

Figure 15. Attainment of goals of residents by goal area. 
graphically in Figure 15. "There are no apparent trends in the 'individual residents' scores. When computed for the group, the trends are mare noticeable. The scores tend to be more even for the group than for any of the individual residents. The range on the four frequently used goal areas is from 2.67 to 2.80 . The tendency is for scores to fall slightly below the expected level of outcome in the primary goal areas.

The data in Figure 15 also demonstrates more consistency in the scores for the group in each goal area than it does in the scores between individual residents. We can collapse the data further into four catagories-Financial, Educational/Vocational, Post-Placement Living, and Personal Goals--to refleot the four primary goal areas of the IPO program. This can be done by combining the Job, Job Searoh, and Financial catagories. The figures are then Financial 2.73, Educational/Vocational 2.80, Post-Plaoement Living 2.50, Personal 2.67. The conclusion from these figures is that the Hawthorne House staff is delivering quite consistently in the four areas in which it is committed to providing service.

\section{Residents' Performance By The Week}

The. attainment data can also be used to evaluate the progress of the residents and the weekly functioning of the house. Table VII, "Goal Attainment Scores for Residents by the Week," provides a tabulation of data over the eleven week evaluation period. The Table indicates the mean attainment score of each resident each week. The right hand marginals are the mean score of each resident for the entire evaluation period. The weekly group means are indioated at the bottom. 
TABLE VII

GOAL ATTAINMENT SCORES FOR RESIDENTS BY THE WEEK

\begin{tabular}{|c|c|c|c|c|c|c|c|c|c|c|c|c|}
\hline \multirow[t]{2}{*}{ Resident } & \multicolumn{11}{|c|}{ Week } & \multirow[t]{2}{*}{ Mean } \\
\hline & $1 / 12$ & $1 / 19$ & $1 / 25$ & $2 / 2$ & $2 / 9$ & $2 / 16$ & $2 / 23$ & $3 / 2$ & $3 / 9$ & $3 / 16$ & $3 / 23$ & \\
\hline A & 3.0 & 3.67 & * & 3.53. & * & 3.67 & 1.00 & 4.00 & 1.25 & 2.5 & 1.33 & 2.22 \\
\hline . B & 4.0 & 2.0 & 2.0 & 2.75 & 2.75 & 2.5 & 2.5 & 5.0 & 5.0 & 3.5 & * & 3.22 \\
\hline$c$ & 2.67 & 3.75 & 3.0 & 3.0 & 3.0 & 2.83 & 3.0 & 3.3 & 1.95 & 2.75 & 2.9 & 2.89 \\
\hline$D$ & 2.67 & 3.0 & * & 3.25 & 3.0 & 1.75 & 3.0 & * & 3.5 & 3.77 & 3.0 & 3.01 \\
\hline$E$ & * & * & 3.25 & 2.0 & 1.67 & 1.5 & 2.5 & * & 2.0 & 3.0 & 1.8 & 2.36 \\
\hline Group & 2.89 & $3 \cdot 3$ & 2.8 & 3.18 & 2.63 & 2.75 & 2.57 & 3.89 & 2.49 & 2.77 & 2.24 & 2.75 \\
\hline
\end{tabular}

* Attainment score not available 
The individual goal attainment scores cover the entire range of 1.00 to 5.00 . The fluctuations show no specific trends when viewed by individual residents. When the data is computed for the group, we do see some trends. The weekly attainment soores for the composite group tend to be consistent at slightly below the expected level of attainment.

The trends are more apparent by looking at Figure 16, "A Graphic Profile of Attainment Scores for Residents by the Week." This figure compares the weekly attainment scores of each resident and of the group over the eleven week period. This refleots the variety of individual attainment scores and the substantial regression toward the mean when computed as a group.

The residents do not show any trends toward increased or decreased attainment scores over time. They do show a tendency to center around the expeoted level of outcome. This reflects realistio goal setting overall by the residents and staff together. The regression toward the expected level of outcome indicates the relatively consistent operation of the house despite the wide fluotuation in individuals. The data provides evidence that the Ilawthome House is operating consistently and effectively in helping residents meet their individual weekly goals.

\section{OVERALI PROGRAM EVALUATION DESIGN}

The data from the attainment scores on long-term goals provide a means for assessing the effectiveness of the program in achieving its goals. There are two ways that the data can be used to develop 


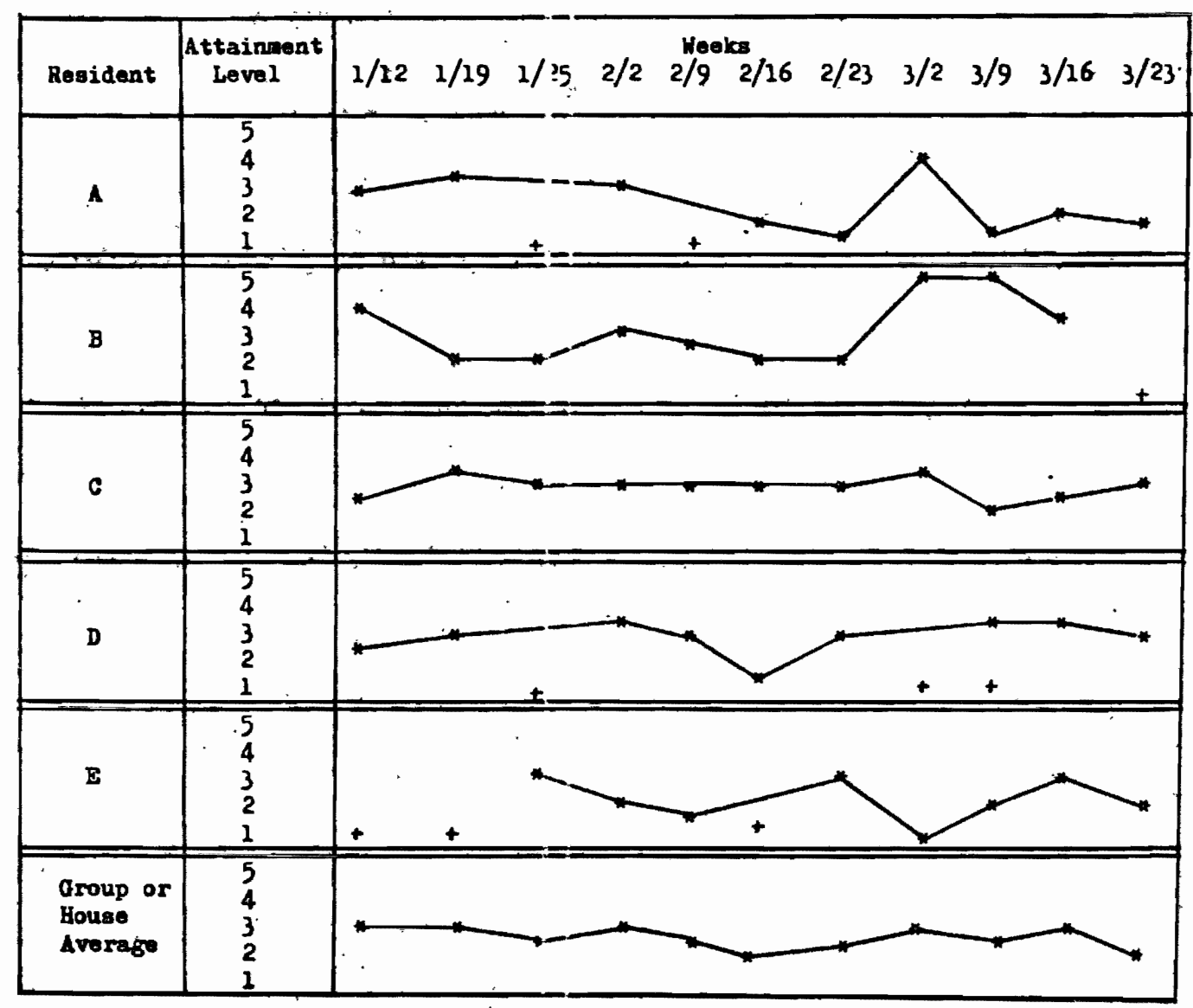

Figure 16. A graphic profile of attainment scores for residents by the week.

+ No attainment score available 
develop indicators toward the program goal. The following discusses these. two methods.

Percentages - The first mothod is to determine the percentage of residents who attain the expected. level of outoome. The percentage figure is determined by marking the outcome level on the long-term IPO follow-up guide at the time the resident leaves the program. The follow-up guides are reviewed to determine the number of scales marked at the expected level or higher. The number is converted to a percentage figure. An example of the review finding could be:

$70 \%$ of the goals set by the residents completing the program between July 1, 1975 and June 30, 1976 were attained at the expeoted level or higher.

Numerioal Score - The second method would utilize data from numerical soores. The scores are computed on long-term goals using the same scoring procedure employed on the weekly IPO's. The scores are tabulated and the mean attainment soores are computed from the data. The mean is computed for all goals of residents completing the program and for each goal area. The mean scores are then compared to target scores set by the program. A target score could be for example:

A mean attainment score of 2.60 for all residents completing the prograin between July $i, 1975$, and June 30, 1976.

Data from both methods of measurement can be incorporated into traditional program evaluation formats. . An example of incorporating attainment data into the Janis' POPS format is provided below. The productivity indicators listed are supplemental to the already existing indicators for the program. 
Program Goal:

Janis seeks to reduce the level of sooial dependency and to

increase the level of self-sufficiency among the target population.

Objeotive \#1:

To reduce and alter the pattern of social and anti-sooial behavior of Janis partioipants.

Productivity Indicators

a) The percentage of residents attaining the expected level of outcomes on Personal growth goals on long-term IPO's.

$$
\text { Target - 80\% }
$$

b) The mean attainment score on the personal growth goals on long-term IPO's.

$$
\text { Target Score }-2.80
$$

\section{Objective \#2:}

To improve the educational and/or vocational related skills of Janis participants.

Productivity Indicators

a) The peroentage of residents attaining expeoted level of outcome educational/vocational long-tern IPO goals.

$$
\text { Target - } 80 \%
$$

b) The mean attainment score on educational/vocational goals on long-term IPO's.

$$
\text { Target Score }-2.75
$$

Objective \#3:

To obtain and maintain employment for those Janis participants not in eduoational or training programs.

Produativity Indicators

a) The percentage of residents attaining the expected level of outcome on financial independence goals on long-term IPO's

$$
\text { Target - 80\% }
$$

b) The mean attainment score on financial independence goals on long-term IPO's.

$$
\text { Target-mean score }-2.75
$$


Objective \#4:

To maintain Janis residential graduates in a stable living situation for one year after graduation from residential program.

Productivity Indicators

a) The percentage of residents attaining the expeoted level of outcome on post-placement living goals on long-term IPO's

$$
\text { Target - } 80 \%
$$

b) The mean attainment score of residents on post-placement living goals on long-term IPO's.

$$
\text { Targot-mean Score - } 2.75
$$

The numerical system provides a more specific indication of how the program functions. If some residents soore very high and some score low the mean gives credit to both groups. The percentage figure may be somewhat misleading, if one-half the residents score at level two and one-half score at level four. The percentage indicates $50 \%$ of residents meeting their goals. It does not give credit to the continuum aspect of scaling. A numerical scoring would give the program a mean attainment score of 3.0 , or expected level of outcome. The two methods emphasize different aspects of the functioning of the IPO system.

There are some cautions that must be dealt with in using the attainment scores for program evaluation. Long-term goals can be changed during the course of the residents stay. The program must allow for changes in goals but must be careful not to allow goals to be lowered toward the end of the residents stay to artificially increase the attainment acore. Secondly, the staff must be cautious about altering the time frame for the resident. The extensions of the resident's stay to provide him more time to complete his goal will 
create higher attainment scores. The program needs to decide when changes are necessary for treatment purposes.

The evaluation instrument should be used to provide the data that is most useful to the program; to be useful it must require a minimum of staff time. Janis will probably never have an extensive research staff. The two evaluation methods outlined in this seotion can be done with a minimum of staff time. 


\section{CHAPTER VIII}

\section{CONCLUSIONS AND IMPRESSIONS}

In terms of the contract with Janis, the commitments were met by both the Janis staff and the researchers. The program developed is now in operation and is effective. The development went smoothly. The Janis program decentralization allowed the House to develop a system out of need and relevance. The experience in developing the program has brought to light many implications about the programs strong points and areas of ooncern. This ohapter disousses these implications and the conclusions of the researohers.

\section{STRONG POINTS IN THE PROGRAM}

The IPO program provides benefits in three areas: 1) management of the House treatment program; 2) direct therapeutic value to the resident; 3) administrative use in planning and evaluation.

\section{House Troatment Program}

The IPO strengthens the treatment process of the House, providing a systematio, measurable system to support the general Glasiser framework of Janis. The specificity of the IPO gystem reduces the vagueness and ineffectiveness of looser contract systems. It maintains the resident's responsibility for his treatment, and brings the treatment purpose of Janis into constant awareness of the resident. The IPO program provides staff feedbaok on how the resident is functioning. 
It makes the framework for assignment of large consequences more explicit and clear, particularly in releasing residents from the program for failure to meet program expectations.

The IPO provides a tool, the mutual planning conference; for disoussing the behaviors and problem areas with the resident. The conference and the follow-up guide focusing on what is important to the resident, providing a less threatening atmosphere for the resident to explore his behavior.

The planning and commitment aspects of the IPO provide a time structuring function for the resident (planning their week). The time stmucturing element of the IPO has become an important aspeot of the Hawthorne House program. The planning function can consume considerable staff time if it is not done in this gystematio way.

Finally, the IPO program, because it is highly structured, provides consigtency in the way the staff deals with the residents. This consistency is orucial in dealing with adolescents.

\section{Therapeutic To Residents}

The prograp value, in and of itself, has therapoutic value to the residents. It helps bring about fundemental change in the way that the resident sees himself. The target population is one of drug abusers. The goals focus away from delinquency issues and allow the resident to see himself outside of the delinquenoy label. The success experience as indicated before, also helps build the new self-image. The scaling process contains benefits. It helps ohange the dichotomous thinking common to acting out adolescents. It focuses on a range of outoome behaviors, rather than using a simple pass-fail 
system.

The process of goal setting brings a time perspective to residents, It helps them foous on the future. It helps them learn how to set their own goals and to break the goals into small steps in order to make them achievable.

\section{Administrative Benefits}

The benefits to the administration lie in the straight-forward evaluative system of the IPO, and in the information provided by the system. The evaluative system has been thoroughly disoussed elsewhere. The information gathering funotion provides a qualitative statement about the program. The IPO gystem allows the program direotors to see beyond the erratio performance that is typical of adolescents and look at group functioning. If the group is functioning oonsistently, the program is operating effeotively and within acceptable iimits. The researoh projeot indicates this is true in the Hawthorne House program. If the group performance beoomes erratic, the IP0 system provides feedback to locate the trouble spots; such as, goals set too high, goals set too low, lack of resident involvement in goal setting, individual members who oonsistently pull the group down, etc. The information would not be available in a less structured system.

II. CONCERNS IN USING THE IPO SYSTEM.

Several cautions must be given in terms of the system described in this paper. These concerns are dealt with below. First, there are validity difficulties of which staff using the instrument must be aware. The goals used by the resident may not 
be valid. The IPO process presupposes that the adolescent can and will know what he wants, and that once he knows, the goal will remain relevant. In actuality this might not be the case. If the resident's goal is not relevant, the resident's commitment will be lacking. The score is only valid if the goal is realistic, and relevent. The validity will be undermined if staff or resident underestimate or overestimate their capabilities. In other words, the score reflects the quality of the goal selection prooess as much as it does the performance or progress of the resident.

Another area of concern is the amount of staff time and skill involved in the process. It requires about four hours a week per staff member to manage the weekly IPO's. And prior to the actual use, several months of training are required for staff to develop skills in scaling. The time commitment can be a liability unless the staff is very much invested in the tool, as the Hawthorne House staff was.

The final concern is the difficulty of balancing flexibility and stability in a treatment program for essentially labile adolescents. The inflexibility of goals can be useful in leveling the mood swings but can also render the goal irrelevant to the resident. The concern is probably best dealt with by assessing the situation cautiously before allowing changes in resident goals.

\section{SUMMARY}

The strength's of the IPO program are real, so are the concerns. The balance is in favor of the strengths, if some precautions are taken. The attainment scores, though, should not be used as the only measure 
of program success because of the validity concerns. The IPO system provides an explicit structure to make the treatment environment more predictable. This is probably the most forceful overall impact of the IPO program.

The IPO system has been developed and tested in one House of the Janis program. Two other Houses are now ready to utilize the system. It is not expected that the system outlined in this paper will be transferred in toto. Nor is it expeoted that the system will remain forever unchanged in the Hawthorne House. The program, to remain relevant, has to allow for changing resident needs and changing staff energies. 
- Audette, D., "Aotivities of the Follow-Up Unit," P.E.P. Report, 1969 - 1973, Program Evaluation Projeot: Minneapolis, Minn., June, 1974, Chapter Two.

- Audette, D., \& G. Garwick, Interview Procedures For Scoring The Goal Attainment Follow-Up Guide, Program Evaluation Project: Minneapolis, Minn., July, 1973.

- Baxter, J., GAS Conversion Key For Equally Weighted Scales, Program Evaluation Project: Minneapolis, Minn., February, 1973.

- Case Management Correction Services. "Individual Plans and Outcomes Manual:" Requests can be made to: Case Management Correotions Services, 8916 N. Woolsey Avenue, Portland, Oregon 97203. January, 1974.

- Case Management Correction Services. "An Overview." Requests oan be made to: Case Management Correction Services, 8916 N. Woolsey Avenue, Portland, Oregon 97203. April, 1973.

- Cline, D., D. Rouzer, \& D. Bransford, "G.A.S. As A Method of Evaluating Mental Health Programs," The American Journal of Psychiatry, Vol. 130, No. 1, Jan., 1973.

- Davis, H.R., "Four Ways to Goal Attainment Scaling," Evaluation, 1973, Vol. 1, No. 2, pgs. 43-48.

- Garwick, G., Commentaries On Goal Attainment Scaling, P.E.P., 1972. , "An Introduction to Reliability and the Goal Attainment Methodology," P.E.P. Report, 1969 - 1973,

, \& S. Lampman, Dictionary of Goal Attainment Scaling, Program Evaluation Projeot: Minneapolis, Minn., 1973. , Guide To Goals, P.E.P., 1972.

, M. Grygelko, W. Makela, \& S. Jones, Preliminary Working Paper on the Manual For The Standardized Assessment of the Goal Attainment Follow-Up Guide. P.E.P., Minneapolis, Minn., July, 1972. 

- Programmed Instruotion In Goal Attainment Soaling, P.E.P., September, 1973.

Glasser, W., Reality Therapy: A New Approach To Psyohiatry, Harper \& Row: New York, 1965.

Janis Project, "Janis Project." Requests can be made to: The Janis Project, 1942 N.W. Keamey, Portland, Oregon 97209.

- Janis Project, "Janis: Progress Report." Requests can be made to The Janis Project, 1942 N.W. Kearney, Portland, Oregon 97209. April, 1973.

Janis, Project, "Janis Drug Abuse Services Project." Requests can be made to The Janis Project, 1942 N.W. Kearney, Portland, Oregon, 97209. September, 1974.

- Kiresuk, T. J., "Basic Goal Attainment Scaling Procedures," P.E.P. Report, 1969 - 1973, 1974, Chapter One.

- Follow-Up Packet, Program Evaluation Project: Minneapolis, Minn.

- Kiresuk, T. J., \& R. E. Sherman, "Goal Attainment Scaling: A General Method For Evaluating Comprehensive Community Mental Health Programs," Community Mental. Health Journal, Vol. 4, No. 6, 1968.

- Kiresuk, T. J., Program Evaluation Project Conference Reports, Program Evaluation Project: Minneapolis, Minn., September, 1973.

- Kiresuk, T. J., The Program Bvaluation Projeot: Overview. Program Evaluation Project: Minneapolis, 1972.

- Lampman, S. \& G. Garwick, Expectations and Goals For Clients At A Comnunity Mental Health Service. Prograin Evaluation Project: Minneapolis, Minn., July, 1972.

Multnomah County Community Action Agency. "Janis: A Drug Treatment Proposal." Request can be made to The Janis Project, 1942 N.W. Kearney, Portland, Oregon 97209. December, 1971

Sherman, R., J. Baxter, \& D. Audette, "An Examination of the Reliability' of the Kiresuk-Sherman Goal Attainment Score By Means At Components of Variance," Program Evaluation Project Report, 1969 - 1973, August, 1974, Chapter Four. 
APPENDICES 
APPENDIX A

CONTRACT FOR SERVICE

\section{Program}

A Sooial Work research practicum in developing a Goal Attainment Soaling system in a pilot project for the Hawthorne House of the Janis program,

Problem Statement

A problem for the Hawthome House with a resident population of adolescent drug offenders is:

A. Lack of objective data on client movement.

B. Lack of consistent, struotured treatment planning.

C. Difficulty focusing treatment planning on positive achievements and away from problem identifioation.

D. Resident population with orientation to failure, and little goal setting experience.

\section{Program Development}

GOAL: To modify the GAS to make it applicable to the Janis Program, as a tool for involving residents in setting and reaching their own positive goals, and also provide a research tool for assessing the Program services in helping residents meet their own goals.

\section{Objectives}

A. To provide a resource file of materials conceming GAS. 
B. To provide a written guide for construction of soales.

c. To develop scale essessment services and provide these services to the Hawthorne House for a three month period.

D. To incorporate long-range and short-term IPO's into a consistent overall treatment plan.

E. To standardize the selection of goal areas for resident partioipants.

F. To provide a collection of sample soales for reference in scale construction.

G. To provide an evaluation design for the GAS program.

H. To provide statistical analysis and descriptive date on GAS program through Maroh, 1975.

I. Provide written statement on the Janis GAS Program. 
APPENDIX B

SCALE CONSTRUCTION GUIDE

\section{PURPOSP}

The purpose of the Guide is to help develop a useable goal attainment soaling system for the Janis Program. This Guide is being d'eveloped for the Hawthorne House to be revised for general applicability to other Janis houses.

\section{General Information About Goal Attainment Scaling}

Goal Attainment Scaling is a tool developed by the Minneapolis based Program Evaluation Projeot for use with reoipients of Out-patient mental health services during treatment. The tool provides a multivariable scaled description continuum which can be used to identify problems, define the treatment objectives, and provide an outcome messurement.

G.A.S. is construoted so that the expeotations of the treatment outcomes are specified on a five point scale ranging from the most favorable to the least favorable outcomes for each area of client concern toward whioh treatment is directed. The scale is construoted Bo that the mid-point is the most likely outcome of treatment.

There are four basio steps involved in goal attainment scaling. First is oolleotion of information about individuals for whom goals will be soaled. Seoondly, the speoification of areas where onange for 
the individual would be realistic and helpful. Thirdly, development of specifio predictions for a series of outcome levels for each area. Lastly, the scoring of the outcomes as they are achieved within the specified time.

\section{JANIS APPLICABILITY}

The original G.A.S. model has been modified to meet the particular needs of Janis. The following are speoific requirements for application of G.A.S. to Janis.

1. Mutual Planning:

The resident and the houseparent establish goals together. A large part of the therapeutio content of the program involves the resident seleoting and reaching his own goals with the help of the staff.

2. Achievable Goals:

Goals must be seleoted which are achievable within the time frame. The therapeutic value is destroyed if suocess is not experienced by the resident on weekly goals. Sucoess breaks the resident's cycle of failure.

\section{Positive Goals:}

The goals should be stated in the positive, related to things that the resident wants to achieve. Avoid focusing on problems partioularly drug and legal problems. Avoidance of a negative behavior is not considered a positive goal.

4. Ube of Coordinated Long-Range and Short-Term Goals:

Janis will couple the long-range treatment length goal system with a weekly goal system. This will provide the overall measurement of a goal aohievement during treatment with the therapeutic experienoe of goal development and attainment on a woekly, immediate basis.

\section{Client As Information Source:}

Goals should be construoted with it kept in mind that the resident will be the principal source of information on achievement. It is possible to use collateral sources. 
If collateral sources are to be used this should be indicated on the I.P.O.

6. A minimum of three scales are to be used on long-range and short-term I.P.Q's. No maximum is set, but four is a convenience maximum since this is the limit for one form.

\section{Completion Process}

1. Use weekly I,P.0. Planning Sessions to define goal areas and objectives. Help resident define objeotive in concise measurable form to use as expected level of success.

2. Establish time length for scale. Developing outcome scale using the following steps:

a. establish expected level of success as mid-point.

b. establish most and least likely extremes.

c. establish more and less than expected oútcomes.

3. Conduct follow-up interview at end of time period specified. Obtain information on performance. Mark outcome level on each soale of I.P.O.

\section{SPECIFIC CONCERNS IN SCALE CONSTRUCTION}

1. Date each I.P.O. indicating when the goal was contracted and when it is to be reviewed.

2. Soales must contain clear, observable indicators, such as behaviors, actions, material production, so that any outside person could score them.

3. Scales should contain only one major indicator unless several indicators would consistently vary together or demonstrate a logical progression.

4. Only üse scales for whioh you can find clear indicators.

5. Carry the same indicator through all levels of the scale.

6. Use numerical measurements for level determination rather than comparatives, or percentages. 
7. Write levels so that an eight year old could understand with clear simple words, avoid abbreviatives, jargon, etc., be specific.

8. Avoid any causal implications in the scales. The cause of behavior change is unimportant and probably cannot be accurately measured.

9. Complete both extremes on each scale making the extremes possible but also exhaustive: such as, three or less items or twelve or more items.

10. Complete all five levels to each scale even if one level could be clearly inferred from it's neighboring levels.

11. Write legibly: 
APFENDIX C

IESCRIPTION OF CATEGORTES OF PROBLEMATIC FEATURES AND THE RECOMMENDED POINT DHDUCTION

ASSOCIATED HITH EACH CATEGORY

\begin{tabular}{|c|c|c|c|}
\hline $\begin{array}{l}\text { Capital letter } \\
\text { Designation } \\
\text { Por Gategory }\end{array}$ & \multirow[t]{2}{*}{$\begin{array}{l}\text { Items Inoluded on Goal } \\
\text { Attainment Pollow-Up } \\
\text { Ouide Aseegent form }\end{array}$} & \multirow[t]{2}{*}{$\begin{array}{l}\text { Reason for Iholusion of } \\
\text { This Item on the Assesement } \\
\text { Form }\end{array}$} & $\begin{array}{l}\text { Recommended System of } \\
\text { Point Deduotions } \\
\text { (Pre-Negotiation) }\end{array}$ \\
\hline & & & $\begin{array}{lc}\text { Pirot } & \text { Bach } \\
\text { Odourrenoo } & \text { Subsequent } \\
& \text { Ocourrence } \\
\end{array}$ \\
\hline $\begin{array}{l}\text { A } \\
\therefore \\
\therefore\end{array}$ & $\begin{array}{l}\text { Request oonfirmation } \\
\text { that follaw-up suido } \\
\text { is oxhnustive, or } \\
\text { request additional }\end{array}$ & 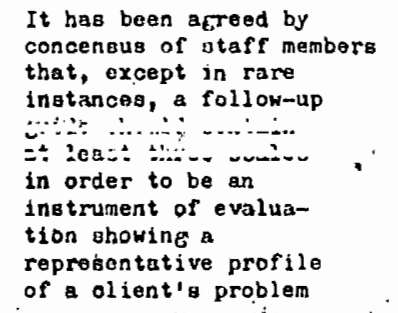 & 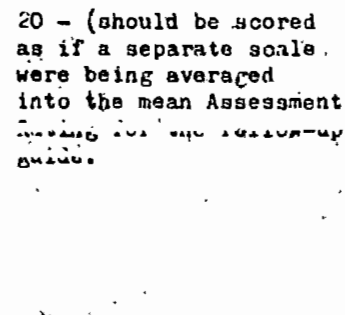 \\
\hline B & $\begin{array}{l}\text { Two adjacent blank } \\
\text { oelis } \\
\\
:\end{array}$ & $\begin{array}{l}\text { A scale on which two } \\
\text { adjacent cella are } \\
\text { blank does not eive } \\
\text { oufficient cues for } \\
\text { follow-up scorint, so } \\
\text { that the follow-up } \\
\text { guide is confusing and } \\
\text { too variable. }\end{array}$ & -20 \\
\hline C & $\begin{array}{c}\text { Extrapolation posai- } \\
\text { bilities unclear. } \\
\\
\text { : }\end{array}$ & 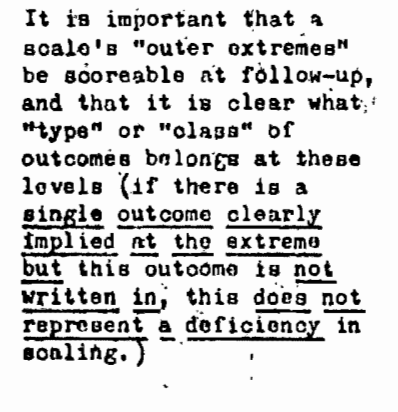 & -4 \\
\hline
\end{tabular}




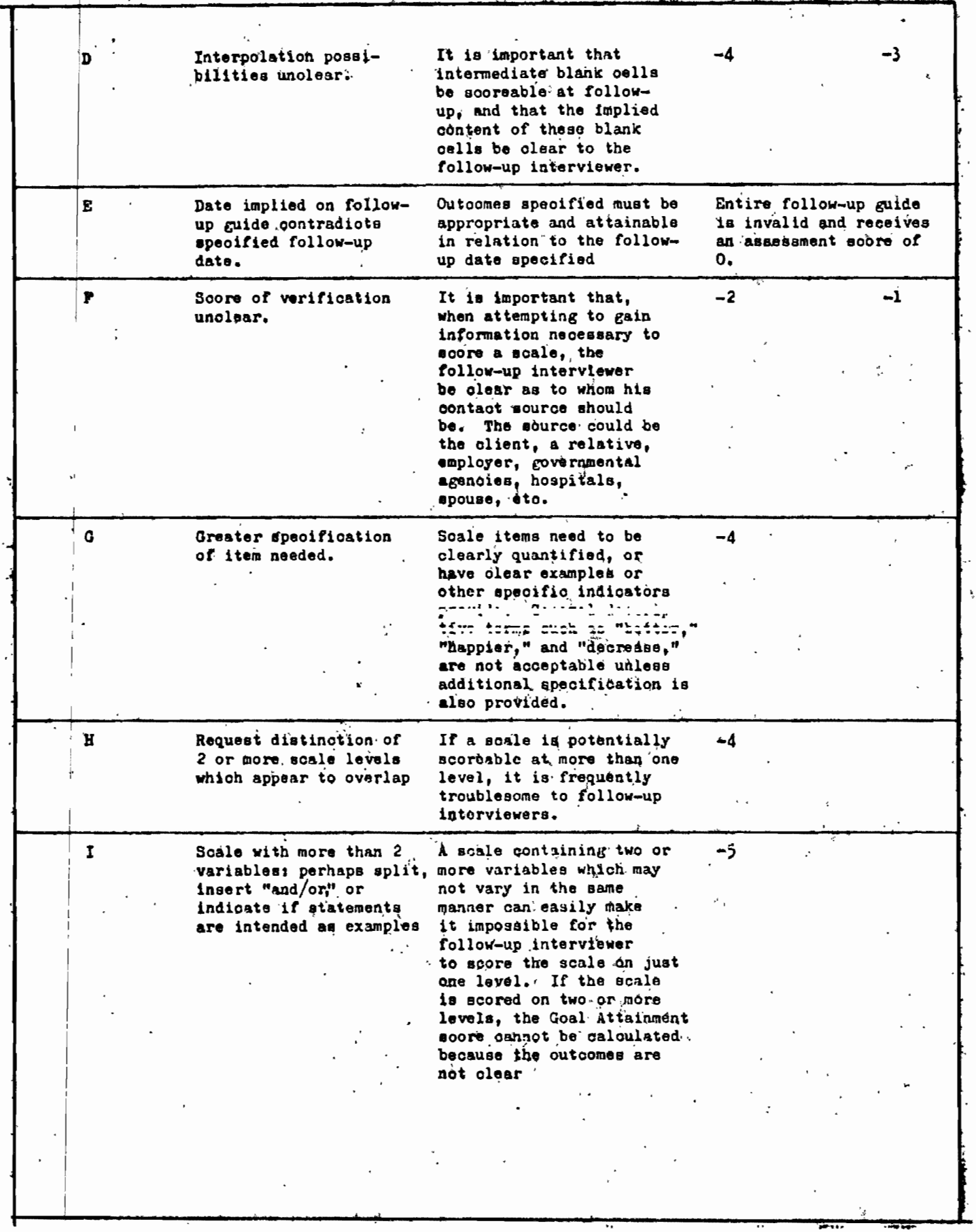




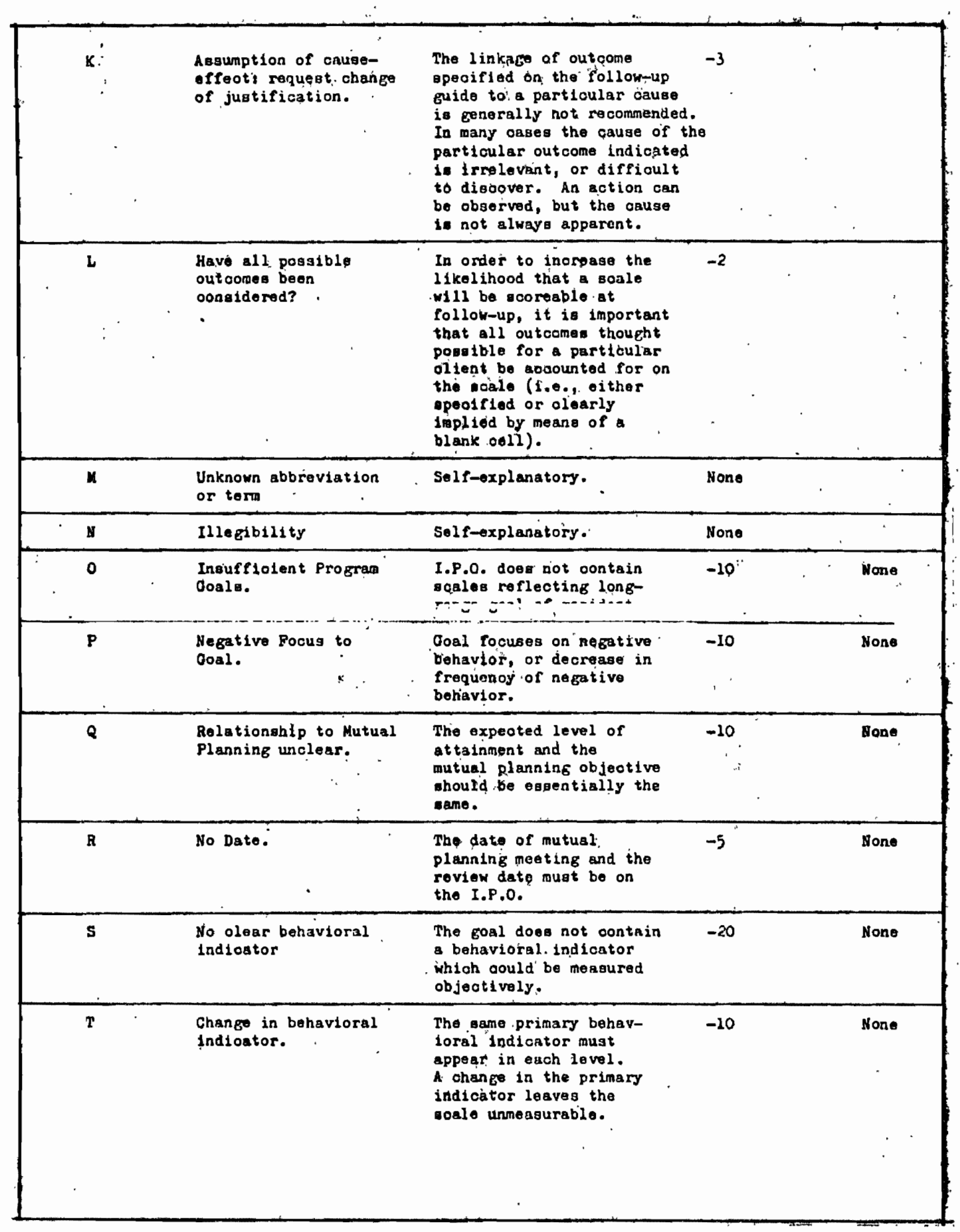




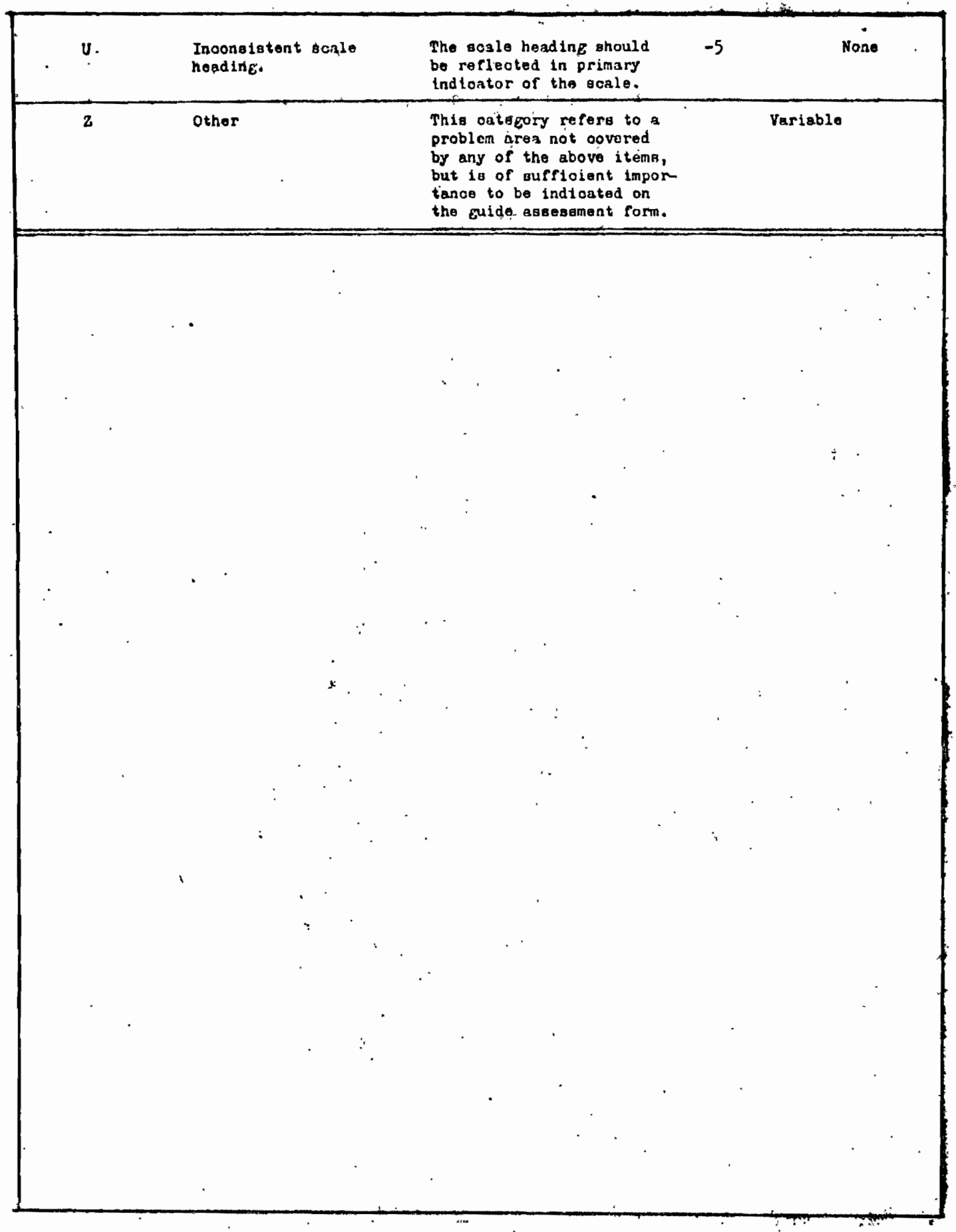

